КЛИНИЧЕСКИЕ РЕКОМЕНДАЦИИ ЩПРЕЖДЕВРЕМЕННОЕ ПОЛОВОЕ РАЗВИТИЕ»

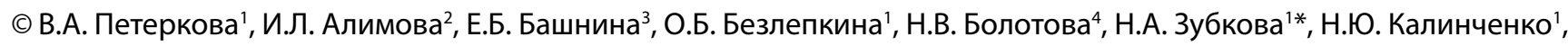

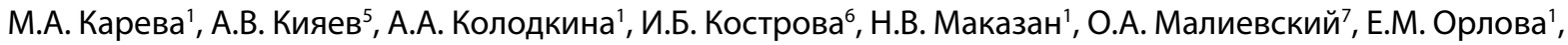
Е.Е. Петряйкина ${ }^{8}$, Л.Н. Самсонова9 ${ }^{9}$ Т.Е. Таранушенко ${ }^{10}$



Преждевременное половое развитие является актуальной проблемой детской эндокринологии, характеризующейся клинической и патогенетической гетерогенностью. Появление вторичных половых признаков ранее 8 лет у девочек и 9 лет у мальчиков требует своевременной диагностики и назначения патогенетически обоснованного лечения с целью достижения целевых показателей конечного роста и предотвращения социальной депривации. Разработанные клинические рекомендации являются основным рабочим инструментом практикующего врача. В них кратко и структурированно изложены основные сведения об эпидемиологии и современной классификации преждевременного полового развития, методах его диагностики и лечения, базирующихся на принципах доказательной медицины.

КЛЮЧЕВЫЕ СЛОВА: клинические рекомендации; преждевременно половое развитие; дети.

\title{
CLINICAL GUIDELINES «PRECOCIOUS PUBERTY»
}

(c) Valentina A. Peterkova1, Irina L. Alimova², Elena B. Bashnina ${ }^{3}$, Olga B. Bezlepkina', Nina V. Bolotova4 , Natalia A. Zubkova ${ }^{1 *}$, Natalya U. Kalinchenko', Maria A. Kareva', Alexey V. Kiyaev', Anna A. Kolodkina', Irina B. Kostrova ${ }^{6}$, Nadezhda V. Makazan', Oleg A. Malievskiy ${ }^{7}$, Elizaveta M. Orlova' ${ }^{1}$, Elena E. Petryaykina ${ }^{8}$, Lyubov N. Samsonova ${ }^{9}$, Tatiana E. Taranushenko ${ }^{10}$

${ }^{1}$ Endocrinology Research Center, Moscow, Russia

${ }^{2}$ Smolensk State Medical University, Smolensk, Russia

${ }^{3}$ North-Western State Medical University named after I.I. Mechnikov, St. Petersburg6 , Russia

${ }^{4}$ Saratov State Medical University named after V. I. Razumovsky, Saratov, Russia

${ }^{5}$ Ural State Medical University, Ekaterinburg, Russia

${ }^{6}$ N. M. Kuraev Children's Republican Clinical Hospital, Makhachkala, Russia

${ }^{7}$ Bashkir State Medical University, Ufa, Russia

${ }^{8}$ Russian Children's Clinical Hospital, Pirogov Russian National Research Medical University, Moscow, Russia

${ }^{9}$ Russian Medical Academy of Continuous Professional Education, Moscow, Russia

${ }^{10}$ Krasnoyarsk State Medical University named after V. F. Voino-Yasenetsky, Krasnoyarsk, Russia

The precocious puberty is an urgent problem of pediatric endocrinology characterized by clinical and pathogenetic heterogeneity. The appearance of secondary sex characteristics before the age of 8 years in girls and 9 years in boys requires timely diagnosis and the appointment of pathogenetically justified treatment in order to achieve the target indicators of final growth and prevent social deprivation. The developed clinical guidelines are the main working tool of the practitioner. They briefly and structurally present the main information about the epidemiology and modern classification of precocious puberty, methods of its diagnosis and treatment based on the principles of evidence-based medicine.

KEYWORDS: clinical guidelines; precocious puberty; children. 


\section{СПИСОК СОКРАЩЕНИЙ}

МКБ 10 - международная классификация болезней 10-го пересмотра

ППР - преждевременное половое развитие Синдром МОБ - синдром МакКьюна-ОлбрайтаБрайцева

$\begin{array}{ll}\text { ГГ } & \text { - гипоталамическая гамартома } \\ \text { СВ } & \text { - синдром Вильямса } \\ \text { УДД } & \text { - уровень достоверности доказательств } \\ \text { УУР } & \text { - уровень убедительности рекомендаций } \\ \mathrm{GPP} & \text { - сложившаяся клиническая практика } \\ \text { ГнРГ } & \text { - гонадотропин-рилизинг-гормон } \\ \text { ХГЧ } & \text { - хорионический гонадотропин человека } \\ \text { ФСГ } & \text { - фолликулостимулирующий гормон } \\ \text { ЛГ } & \text { - лютеинизирующий гормон } \\ \text { ДГЭА } & \text { - дегидроэпиандростерон } \\ \text { ДГЭА-С - дегидроэпиандростерон сульфат } \\ \text { ВДКН - врожденная дисфункция коры надпочечников } \\ \text { ЦНС } \quad \text { - центральная нервная система }\end{array}$

\section{ТЕРМИНЫ И ОПРЕДЕЛЕНИЯ}

Преждевременное половое развитие - это появление вторичных половых признаков у девочек до 8 лет и у мальчиков до 9 лет.

Гонадотропин-зависимое (центральное, истинное) преждевременное половое развитие - это появление вторичных половых признаков у девочек до 8 лет и у мальчиков до 9 лет, обусловленное преждевременной активацией гипоталамо-гипофизарной системы.

Гонадотропин-независимое (периферическое) преждевременное половое развитие - это появление вторичных половых признаков у девочек до 8 лет и у мальчиков до 9 лет, обусловленные автономной секрецией половых стероидов гонадами, стероид-секретирующими опухолями гонад или надпочечников, избыточной секрецией андрогенов надпочечниками вследствие нарушений стероидогенеза, ХГЧ-секретирующими герминативно-клеточными опухолями, декомпенсированным первичным гипотиреозом.

Преждевременное изолированное телархе - изолированное появление железистой ткани молочных желез у девочек до 8 лет без других клинико-лабораторных признаков преждевременного полового развития.

Преждевременное изолированное адренархе изолированное появление лобкового оволосения у девочек до 8 лет без других клинико-лабораторных признаков преждевременного полового развития.

\section{1. КРАТКАЯ ИНФОРМАЦИЯ ПО ЗАБОЛЕВАНИЮ ИЛИ СОСТОЯНИю.}

1.1. Определение заболевания или состояния.

Преждевременное половое развитие (ППР) - это появление вторичных половых признаков у девочек до 8 лет и у мальчиков до 9 лет [1-4].

1.2. Этиология и патогенез заболевания или состояния.

Выделяют гонадотропин-зависимую (центральную, истинную), гонадотропин-независимую (периферическую) и парциальную формы ППР.
Гонадотропин-зависимое ППР обусловлено преждевременной активацией центрального звена гипоталамо-гипофизарно-гонадной системы - повышение секреции половых стероидов гонадами при данной форме является следствием стимуляции половых желез гонадотропными гормонами гипофиза. Причиной преждевременного полового развития центрального генеза являются опухоли хиазмально-селлярной области, органическое поражение цНС (арахноидальные кисты, травмы, гидроцефалия), генетические нарушения (активирующие мутации гена-рецептора кисс-пептина GPR54 или гена кисс-пептина KISS1 и инактивирующие мутации гена $M K R N 3$, переданного от отца) $[1,5]$. Центральное ППР с манифестацией в 6-7 лет характерно для синдрома Вильямса, синдрома однородительской дисомии 14 хромосомы материнского происхождения (синдрома Темпла), отмечено при синдроме Сильвера-Рассела [6-9]. Также преждевременная активация гонадолиберин-гонадотропов может возникнуть в ответ на избыток половых стероидов, возникающий при периферических формах ППР [10].

В большинстве случаев причина центрального ППР остается неизвестной, такие случаи называются идиопатическим гонадотропин-зависимым ППР.

Гонадотропин-независимое (периферическое) ППР обусловлено секрецией половых стероидов гонадами или опухолями гонад или надпочечников, избыточной секрецией андрогенов надпочечниками вследствие нарушений стероидогенеза [11].

Активация гонад без стимулирующего воздействия гонадотропинов и в отсутствие опухолей может быть следствием генетических нарушений (тестотоксикоз и синдром МакКьюна-Олбрайта-Брайцева (синдром МОБ)), воздействия на половые железы ХГЧ при герминогенных опухолях или ТТГ при декомпенсированном первичном гипотиреозе.

Тестотоксикоз - заболевание с аутосомно-доминантным типом наследования, возникает вследствие активирующих мутаций в гене LHCGR, кодирующем рецептор ЛГ. Постоянная активация рецептора приводит к стимуляции клеток Лейдига и синтезу тестостерона в яичках, несмотря на низкий уровень ЛГ $[12,13]$.

Синдром МОБ обусловлен активирующими соматическими мутациями гена GNAS, кодирующего стимулирующую альфа-субъединицу G-белка (Gas). Эта субъединица играет важную роль в передаче сигнала от множества пептидных гормонов в клетках-мишенях, в частности от ЛГ и ФСГ. Активация Gas приводит к повышению цАМФ в клетках гонад и продукции половых стероидов в отсутствие стимуляции гонадотропинами $[14,15]$. Клоны клеток с мутантными аллелями распределяются в гонадах неравномерно. У девочек они могут локализоваться в одном или двух яичниках, обусловливая периодическое появление эстрогенпродуцирующих кист с последующим их регрессом. У мальчиков также может возникать периферическое ППР, но чаще наблюдается изолированный макроорхидизм, что отмечается при преимущественном наличии мутаций в клетках Сертоли с меньшим содержанием или отсутствием таковых в клетках Лейдига [16-18].

Кроме синдрома МОБ, вариантом автономной гиперфункции половых желез у девочек является преходящее периферическое ППР вследствие функциональных кист 
яичников, причины появления которых остаются неясными $[19,20]$.

ХГЧ-секретирующие герминогенные опухоли - объемные образования, возникающие вследствие нарушения дифференцировки плюрипотентных зародышевых клеток, возникающие в половых железах или вне гонад по срединной линии тела по пути миграции примордиальных зародышевых клеток [21]. Вырабатываемый опухолью ХГЧ, сходный по структуре с ЛГ, активирует рецепторы к ЛГ в клетках Лейдига в яичках и приводит к повышению секреции тестостерона. При этом, как правило, не происходит значимого увеличения в объеме яичек, так как клетки Сертоли, обеспечивающие сперматогенез, активируются под воздействием ФСГ [22]. ХГЧ-секретирующие герминогенные опухоли вызывают преждевременное половое развитие у мальчиков, тогда как для девочек с этим заболеванием ППР не характерно. Это объясняется тем, что биосинтез эстрогенов в яичниках требует воздействия как ЛГ, так и ФСГ. Тем не менее в литературе есть описание двух случаев периферического ППР у девочек с ХГЧ-секретирующими герминогенными опухолями [23, 24].

Декомпенсированный первичный гипотиреоз также может быть причиной гонадотропин-независимого ППР. Наиболее вероятным механизмом развития ППР в этом случае считается стимуляция значительно повышенным ТТГ рецепторов к ФСГ в гонадах, что становится возможным благодаря наличию одинаковых альфа-субъединиц в структуре ТТГ и ФСГ $[25,26]$. Впервые ППР, обусловленное тяжелым первичным гипотиреозом, было описано в 1960 г. Ван Виком и Громбахом и теперь известно как синдром Ван Вика-Громбаха [27].

Опухоли надпочечников чаще секретируют андрогены, вызывая изосексуальное ППР у мальчиков и гетеросексуальное ППР у девочек, редко могут секретировать эстрогены, что приводит к развитию гетеросексуального преждевременного полового развития у мальчиков и изосексуального преждевременного полового развития у девочек. Среди стероид-секретирующих опухолей яичек чаще встречаются лейдигомы; опухоли яичников могут секретировать как эстрогены, так и андрогены.

Избыточная секреция андрогенов надпочечниками вследствие нарушений стероидогенеза при различных вариантах врожденной дисфункции коры надпочечников приводит к периферическому ППР по типу изосексуального у мальчиков и гетеросексуального у девочек.

Полные формы ППР характеризуются системным воздействием половых гормонов на организм ребенка, что проявляется прогрессирующим развитием вторичных половых признаков и ускорением костного созревания с увеличением скорости роста.

Парциальные формы ППР представляют собой преждевременное изолированное увеличение молочных желез у девочек (изолированное преждевременное телархе) и преждевременное изолированное развитие полового оволосения (изолированное преждевременное адренархе) [1, 28].

Изолированное увеличение молочных желез у девочек рассматривается как следствие транзиторной активации центрального звена гипоталамо-гипофизарно-гонадной оси с преобладающим избытком ФСГ [29].

Изолированное преждевременное адренархе возникает вследствие преждевременного созревания сет- чатой зоны коры надпочечников с повышением уровня дегидроэпиандростерон сульфата (ДГЭА-С), обладающего относительно слабыми андрогенными свойствами. Патогенез преждевременного адренархе остается неясным, на данный момент лишь установлено, что девочки с этим состоянием находятся в группе риске по развитию синдрома поликистозных яичников [30].

\section{3. Эпидемиология заболевания или состояния}

(группы заболеваний или состояний).

Распространенность ППР зависит от нозологического варианта, пола и возраста. Гонадотропин-зависимые формы ППР встречаются у девочек значительно чаще, чем у мальчиков. По данным мировой литературы, распространенность центральных форм ППР у девочек до 2 лет составляет 0,5 случая на 10000 детского населения, от 2 до 4 лет 0,05:10 000, от 5 до 9 лет - $8: 10$ 000. Среди мальчиков ППР встречается реже вне зависимости от возраста - 0,05: 10000 [31].

Гонадотропин-независимое ППР встречается гораздо реже, распространенность зависит от формы заболевания.

1.4. Особенности кодирования заболевания или состояния по Международной статистической классификации болезней и проблем, связанных со здоровьем.

Е30.1 Преждевременное половое созревание.

Е22.8 Преждевременное половое развитие центрального происхождения.

Е28.1 Избыток андрогенов.

E29.0 Гиперфункция яичек.

Е31.1 Полигландулярная гиперфункция.

1.5. Классификация заболевания или состояния.

В основу классификации синдрома ППР положен патогенетический принцип, учитывающий первичную локализацию патологического процесса в системе гипоталамус-гипофиз-гонады-надпочечники.

\section{1. Гонадотропин-зависимое ППР.}

- Гипоталамическая гамартома (эктопия гипоталамической ткани, вызванная патологией миграции нейронов в эмбриональном периоде).

- Объемные образования головного мозга (глиомы, астроцитомы, арахноидальные кисты хиазмально-селлярной области и дна 3 желудочка).

- Органическое поражение цНС (гидроцефалия, лучевая терапия, травма, в т.ч. хирургическая, воспалительное поражение).

- Генетически обусловленное (мутации в генах KISS1, GPR54, MKRN3).

- Обусловленное предварительным избытком половых стероидов, возникающим при периферических формах ППР.

- Идиопатическое ППР.

- Ассоциированное с синдромальной патологией (синдром Вильямса, синдром однородительской дисомии 14 хромосомы материнского происхождения, синдром Сильвера-Рассела).

2. Гонадотропин-независимое половое развитие.

2.1. Обусловленное секрецией половых стероидов гонадами. 
удевочек:

- Синдром МОБ.

- Персистирующие фолликулярные кисты.

- Первичный гипотиреоз (синдром Ван Вика-Громбаха)

Умальчиков:

- ХГЧ-секретирующие опухоли (герминомы).

- Синдром МОБ.

- Тестотоксикоз.

- Первичный гипотиреоз (синдром Ван ВикаГромбаха).

2.2. Обусловленное секрецией половых стероидов опухолями гонад или надпочечников.

- Эстроген-продуцирующие опухоли яичников.

- Андроген-продуцирующие опухоли яичников.

- Лейдигомы.
- Эстроген-продуцирующие опухоли надпочечников.

- Андроген-продуцирующие опухоли надпочечников.

2.3. Обусловленное избыточной секрецией андрогенов надпочечниками вследствие нарушений стероидогенеза (ВДКН) - всегда изосексуальное у мальчиков и гетеросексуальное у девочек.

- Дефицит 21-гидроксилазы.

- Дефицит 11ß-гидроксилазы.

- Дефицит 3ß-гидроксистероид-дегидрогеназы (только у девочек приводит к преждевременному адренархе).

3. Изолированные формы преждевременного полового развития.

3.1. Изолированное преждевременное телархе.

Таблица 1. Классификация преждевременного полового развития

\begin{tabular}{|c|c|c|}
\hline Уровень поражения & Нозологический вариант & Соответствие полу \\
\hline \multirow{8}{*}{$\begin{array}{l}\text { Гонадотропин- } \\
\text { зависимое (центральное) } \\
\text { преждевременное половое } \\
\text { развитие }\end{array}$} & Гипоталамическая гамартома & \multirow{8}{*}{ Всегда изосексуальное } \\
\hline & $\begin{array}{l}\text { Опухоли хиазмально-селлярной области (астроцитома, } \\
\text { глиома и т.д.) }\end{array}$ & \\
\hline & $\begin{array}{l}\text { Врожденные аномалии ЦНС (гидроцефалия, } \\
\text { арахноидальные кисты, супраселлярные кисты, } \\
\text { гранулематозные заболевания) }\end{array}$ & \\
\hline & Приобретенные травмы ЦНС (хирургическое & \\
\hline & вмешательство, облучение, травма, воспаление) & \\
\hline & $\begin{array}{l}\text { Генетически обусловленное (мутации в генах KISS1, } \\
\text { GPR54, MKRN3) }\end{array}$ & \\
\hline & $\begin{array}{l}\text { Ассоциированное с синдромальной патологией } \\
\text { (синдром Вильямса, синдром однородительской } \\
\text { дисомии } 14 \text { хромосомы материнского происхождения, } \\
\text { синдром Сильвера-Рассела) }\end{array}$ & \\
\hline & $\begin{array}{l}\text { Предварительный избыток половых стероидов, } \\
\text { возникающий при периферических формах ППР }\end{array}$ & \\
\hline
\end{tabular}

Мутации в гене GNAS - синдром МОБ:

эстрогенпродуцирующие кисты яичников у девочек/

Гонадотропин-независимое автономная гиперсекреция тестостерона в яичках у мальчиков/макроорхидизм без автономной преждевременное половое развитие, обусловленное автономной секрецией половых стероидов гонадами

гиперсекреции тестостерона у мальчиков

Фолликулярные кисты яичников

Всегда изосексуальное

Мутации в гене LHCGR - семейный тестотоксикоз

ХГЧ-секретирующие герминомы

Первичный гипотиреоз (синдром Ван Вика-Громбаха)

Гонадотропин-независимое преждевременное половое развитие, обусловленное опухолями гонад и надпочечников

\begin{tabular}{l} 
Эстроген-продуцирующие опухоли яичников \\
\hline Андроген-продуцирующие опухоли яичников \\
Лейдигомы
\end{tabular}

Изосексуальное у девочек Гетеросексуальное у девочек Изосексуальное у мальчиков Гетеросексуальное у мальчиков и изосексуальное у девочек

Гонадотропин-независимое преждевременное половое развитие, обусловленное нарушениями стероидогенеза

Формы врожденной дисфункции коры надпочечников Гетеросексуальные (дефицит 21-гидроксилазы) у девочек и изосексуальные у мальчиков

Преждевременное изолированные телархе Изосексуальное у девочек

Неполные (изолированные) формы преждевременного полового развития

Преждевременное изолированные адренархе

Изосексуальное у мальчиков и гетеросексуальное у девочек (надпочечникового генеза) 


\section{2. Изолированное преждевременное адренархе.}

1.6 Клиническая картина заболевания или состояния.

Истинное гонадотропин-зависимое преждевременное половое развитие всегда бывает полным, т.е. у девочек после увеличения молочных желез и ускорения темпов роста появится половое оволосение и наступит менархе, а у мальчиков наряду с увеличением гениталий и ускорением роста будет происходить увеличение объема яичек.

При гонадотропин-независимом половом развитии у мальчиков происходит андрогенизация, однако нет стимулирующего воздействия ФСГ на гонады, вследствие чего не отмечается роста объема яичек; у девочек возможны нециклические менструалоподобные кровотечения, обусловленные резкими колебаниями уровня эстрогенов при кистах яичников или при синдроме МОБ.

\section{Особенности клинической картины при различных} нозологических формах ППР

Гипоталамическая гамартома (ГГ) - наиболее часто выявляемое образование центральной нервной системы (ЦНС) у детей с истинным ППР до 3 лет жизни вне зависимости от пола. ГГ не является опухолью, а представляет собой врожденную эктопию гипоталамической ткани. ГГ в 70\% случаев вызывает ППР [32]. Помимо ППР, гамартомы гипоталамической локализации могут сопровождаться неврологическими и поведенческими аномалиями. Типичным проявлением интрагипоталамического (сесильного) типа гамартом является приступы насильственного смеха (gelastic seizures). Часто отмечаются эмоциональная лабильность, агрессивность, снижение памяти, возможно снижение интеллекта [33, 34].

Глиомы и астроцитомы как причина истинного ППР встречаются значительно реже. Большинство глиом, сопровождающихся клинической картиной ППР, локализуются в области хиазмы и дна 3-го желудочка или распространяются вдоль зрительного тракта. Подавляющее число глиом обладает низкой пролиферативной активностью и представляют собой доброкачественные пилоидные астроцитомы, обладающие тенденцией к медленному росту. Анапластические астроцитомы (злокачественный вариант глиомы) встречается преимущественно у взрослых. На МР-снимках глиомы представляют собой однородную массу, сходную по плотности с веществом мозга. Оптические глиомы небольших размеров могут манифестировать только симптомами ППР, большие размеры опухоли хиазмы и дна 3-го желудочка могут сопровождаться явлениями несахарного диабета, СТГ-дефицита, сужением полей зрения, снижением остроты зрения и общемозговыми симптомами, связанными с повышением внутричерепного давления. Достаточно часто симптомы ППР, или ускоренного пубертата, развиваются сразу после оперативного удаления или облучения глиом хиазмально-селлярной локализации [35].

Синдром МакКьюна-Олбрайта-Брайцева мультисистемное заболевание, компонентами которого являются пятна цвета «кофе с молоком», фиброзная дисплазия скелета, гиперфункция эндокринных желез (гонад, соматотрофов гипофиза, фетальной коры надпочечников, щитовидной железы), а также ряд патологий других органов (тахикардия, холестатический гепатит, гастроинтестинальные полипы, внутрипротоковая папиллярно-муцинозная опухоль поджелудочной железы) $[17,36]$. Фиброзная дисплазия проявляется деформациями верхних конечностей, деформациями нижних конечностей по типу пастушьего посоха, деформациями черепа, патологическими переломами костей, сопровождается гиперфосфатурией с возможностью развития гипофосфатемического рахита [37]. Характерной особенностью периферического ППР при синдроме МОБ у девочек является волнообразное течение с непредсказуемой частотой появления признаков ППР в виде увеличения молочных желез с/или без кровянистых выделений из половых путей [16, 17, 38]. У мальчиков при синдроме МОБ чаще наблюдается макроорхидизм без других признаков ППР и в отсутствие повышения тестостерона [16-18].

Активирующие мутации гена рецептора к ЛГ приводят к периферическому ППР только у мальчиков, и такой вариант заболевания называется тестотоксикоз. Его отличительной чертой является высокий уровень тестостерона при подавленных уровнях гонадотропинов и при размере яичек, не соответствующем повышенным значениям тестостерона (не более 6-8 мл), поскольку основной объем яичек составляют структуры, рост которых стимулируется ФСГ. При данной нозологии отмечается ранняя манифестация (на первом году жизни) и быстрая прогрессия признаков полового развития $[12,13]$.

ХГЧ-секретирующие герминогенные опухоли. В детском возрасте встречаются ХГЧ-секретирующие гепатобластомы, реже медиастинальные тератомы и тератобластомы, ретроперитонеальные карциномы, хориокарциномы и герминомы гонад. Для краниальных ХГЧ-секретирующих опухолей наиболее типичная локализация - пинеальная область, реже супраселлярная цистерна. До 30\% герминативно-клеточных опухолей имеют злокачественный характер. Краниальные ХГЧ-секретирующие опухоли характеризуются многообразной неврологической симптоматикой. При супраселлярной локализации в неврологической симптоматике преобладают симптомы повышения внутричерепного давления и зрительные нарушения, связанные с поражением оптической хиазмы. Возможны эндокринные нарушения: с высокой частотой встречается несахарный диабет, реже - СТГ-дефицит. При опухолях, локализующихся в пинеальной области, ведущей является неврологическая симптоматика, обусловленная сдавлением тенториума: нистагм, парез взора вверх, анизокория, а также выраженные симптомы внутричерепной гипертензии [39].

Синдром Ван Вика-Громбаха характеризует ППР на фоне декомпенсированного первичного гипотиреоза. У девочек отмечаются кровянистые выделения из половых путей, реже - увеличение молочных желез и галакторея, у мальчиков - увеличение в объеме яичек. Костный возраст, как правило, отстает. После назначения заместительной терапии левотироксином натрия симптомы ППР регрессируют [25-27].

Однородительская дисомия 14 хромосомы материнского происхождения, делеции 14 хромосомы отцовского происхождения и нарушения метилирования 
дифференциально метилируемых регионов 14 хромосомы приводят к развитию синдрома Темпла (по имени автора, впервые описавшего это заболевание в 1991 г.), включающего в себя: дефицит веса, пре- и постнатальную задержку роста, гипотонию, акромикрию кистей и стоп, умеренные проявления лицевого дисморфизма, легкую степень задержки умственного развития, преждевременное половое развитие с ранним менархе, которое наступает в возрасте 8-10 лет, сопровождающееся опережением костного возраста в отсутствие значимого ускорения роста $[7,8]$.

Синдром Вильямса (СВ) - это мультисистемное заболевание, обусловленное делециями длинного плеча 7 хромосомы. При СВ отмечается ряд фенотипических черт (характерное «лицо эльфа», пухлые губы и хриплый голос), поведенческих особенностей (чрезмерно дружелюбное поведение, умственная отсталость) и патологий различных органов и систем (надклапанный аортальный стеноз, стеноз периферических легочных артерий, аномалии развития почек, конечный рост ниже среднего и др.). Из эндокринных нарушений при СВ отмечаются гиперкальциемия с манифестацией в первые годы жизни, гипотиреоз, нарушения углеводного обмена, центральное преждевременное половое развитие с манифестацией в возрасте 6-7 лет [6].

Преждевременное изолированное телархе характеризуется увеличением молочных желез до 3 стадии развития по Tanner, без ускорения костного возраста и прогрессии других вторичных половых признаков [29, 40]. Чаще всего возникает в течение первых двух лет жизни и в большинстве случаев регрессирует. После 2 лет также возможно возникновение изолированного телархе, однако в таких случаях повышен риск трансформации изолированного телархе в полную центральную форму ППР [29].

Преждевременное изолированное адренархе не является признаком истинного центрального ППР, так как процесс активации сетчатой зоны коры надпочечников, где образуются андрогены, не регулируется гонадотропными гормонами. Клиническими признаками преждевременного адренархе являются типичные проявления гиперандрогении в виде появления лобкового оволосения, запаха пота и угревой сыпи, также характерно ускорение костного возраста [29, 30, 41]. Преждевременное адренархе - это диагноз-исключение, который может быть установлен только после обследования на предмет других возможных причин гиперандрогении.

\section{2. ДИАГНОСТИКА ЗАБОЛЕВАНИЯ ИЛИ СОСТОЯНИЯ.}

- Рекомендуется обследование детям с клиническими признаками ППР - девочкам с вторичными половыми признаками, манифестировавшими до 8 лет и мальчикам с вторичными половыми признаками, манифестировавшими до 9 лет [5, 10]. УДД - 5, УУР - С

Диагностика ППР происходит поэтапно. На первом этапе необходимо констатировать наличие преждевременного полового развития, выделить группу неполных форм, т.н. изолированное телархе и адренархе. На втором этапе у пациентов с подтвержденным преждевременным половым развитием необходимо установить нозологический вариант с целью определения тактики лечения.
2.1. Жалобы и анамнез.

- При сборе анамнеза рекомендуется уточнить следующие вопросы:

- Сроки появления молочных желез у девочек: появление молочных желез на первом году жизни чаще встречается при изолированном телархе [40, 42] УДД - 4, УУР - С.

- Скорость прогрессии вторичных половых признаков: для овариальных эстрогенпродуцирующих кист яичников характерно интермиттирующее течение полового развития [43-46]. УДД - 4, УУР - С.

Скорость роста за предшествующее 3-6 мес: при преждевременном изолированном телархе и адренархе нет ускорения роста. Отсутствие ускорения роста наблюдается при ППР на фоне гипопитуитаризма при арахноидальных кистах, септо-оптической дисплазии, опухолях ЦНС, после облучения ЦНС и при пороках развития гипоталамо-селлярной области. [47-49]. УДД - 3, УУР - В.

Наличие признаков частых компонентов синдрома МакКьюна-Олбрайта-Брайцева: фиброзная дисплазия и/или пятна цвета «кофе с молоком» с неровными «географическими» краями [16, 17, 50-52]. УДД - 4, УУР - С.

- Наличие неврологической симптоматики и симптомов несахарного диабета: преждевременное половое развитие может быть последствием органического поражения ЦНС $[53,54]$. УДД - 4, УУР - С.

Наличие признаков синдромальной патологии (возможные синдром Вильямса, СильвераРассела, Темпла): стигмы дисэмбриогенеза, отставание в развитии, низкорослость, поведенческие особенности, пороки развития сердца, гиперкальциемия, признаки мышечной гипотонии, низкорослость и т.д.

\section{2. Физикальное обследование.}

- Рекомендуется проводить клиническую оценку полового развития на основании шкалы Tanner всем детям для определения степени полового созревания и ее соответствия возрасту ребенка: степень полового развития Tanner 2 и более у девочек младше 9 лет и мальчиков младше 9 лет является критерием ППР [53, 55, 56]. УДД - 4, УУР - С.

Рекомендуется девочкам младше 8 лет и мальчикам младше 9 лет с клиническими признаками ППР выполнять:

- антропометрию с целью оценки коэффициента стандартного отклонения по росту - превышение роста более 2SD относительного целевого роста на данный возраст является критерием ППР [5, 28, 47]. УДД - 5, УУР - С;

- подсчет скорости роста за предшествующие 6-12 мес с целью определения скорости роста - увеличение скорости роста более 2SD за предшествующий период свидетельствуют в пользу ППР [5, 28, 47]. УДД - 5, УУР - C.

- Рекомендуется мальчикам проводить оценку объема гонад или длину яичка. Несоответствие размера яичек степени полового развития является критерием гонадотропин-независимого преждевременного половом развитии [11]. УДД - 5, УУР - С. 
- Рекомендуется девочкам проводить оценку менструальной функции - наличие менструаций у девочек младше 8 лет является критерием ППР [5, 17]. УДД - 5, уур - С.

\section{Комментарии.}

Дополнительно при осмотре можно выявить сопутствующие симптомы, характерные для отдельных нозологических форм:

- Наличие пятен цвета «кофе с молоком» с неровными географическими краями характерно для синдрома МОБ.

- Наличие округлых/овальных пятен цвета «кофе с молоком», веснушек в подмышечных областях, нейрофибром характерно для нейрофиброматоза 1 типа, при котором развитие ППР обусловлено глиомами зрительного нерва.

- Наличие деформаций костей конечностей по типу пастушьего посоха, деформаций и асимметрий черепа характерно для синдрома МОБ.

- Наличие неврологической симптоматики (нистагм, косоглазие, шаткость походки и т.п.) может свидетельствовать в пользу органического поражения ЦНС.

- Нерегулярные менструалоподобные реакции характерны для синдрома МОБ.

\section{3. Лабораторные диагностические исследования.}

- Рекомендуется девочкам младше 8 лет с клиническими признаками ППР и мальчикам младше 9 лет с клиническими признаками ППР определение уровня гонадотропных гормонов (исследование лютеинизирующего гормона (ЛГ) крови, фолликулостимулирующего гормона (ФСГ) крови и половых стероидов (исследование уровня общего тестостерона в крови, исследований уровня общего эстрадиола в крови) для подтверждения преждевременного полового развития и дифференциальной диагностики его формы [5, 57-61]. УДД - 4, УуР - С.

\section{Комментарии.}

- Наибольшей информативностью в диагностике гонадотропин-зависимого ППР обладает уровень ЛГ, но только при использовании высокочувствительных методик (ICMАС чувствительностью 0,01 Ед/л или ECLIA с чувствительностью 0,1 Ед/л) и наличии в лаборатории допубертатных нормативов.

- Значение ЛГ выше 0,3 Ед/л при использовании вышеуказанных методик с высокой вероятностью свидетельствует о наличии гонадотропин-зависимого ППР [57-60].

- Значение Лг менее 0,3 Ед/л не позволяет исключить гонадотропин-зависимое ППР, так как до 50\% здоровых девочек со второй стадией полового развития имеют допубертатный уровень ЛГ [60, 62-64].
Уровень Лг у здоровых девочек младше 2 лет может соответствовать пубертатным значениям в соответствии с характерным для этого возраста «мини-пубертатом», что следует иметь в виду при интерпретации результатов $[65,66]$.

- У девочек в возрасте до 3 лет с пальпируемыми молочными молочными железами повышенный уровень ФСГ при допубертатных значениях ЛГ указывает на наличие неполной формы ППР - преждевременного телархе [67, 68].

- $\quad$ Рекомендуется девочкам младше 8 лет с клиническими признаками ППР и мальчикам младше 9 лет с клиническими признаками ППР проведение пробы с аналогом гонадотропин-рилизинг-гормона короткого действия с целью дифференциальной диагностики гонадотропин-зависимого варианта ППР и гонадотропин-независимых форм ППР [5, 60, 67]. УДД - 5, УУР - С.

Комментарии. При клинической картине, соответствующей стадии полового развития по Tanner 3 и выше, в сочетании с пубертатным уровнем ЛГ, в проведении пробы с аналогом Гн-РГ нет необходимости.

Методика проведения пробы с гонадотропин-рилизинг-гормоном: определяется базальный уровень ЛГ и ФСГ крови, вводится аналог ГнРГ короткого действия, на фоне стимуляции которым определяется в динамике уровень ЛГ и ФСГ крови. Препараты ГнРГ, использующиеся для пробы, и временные точки забора крови представлены в таблице 2.

Критерии оценки пробы с гонадотропин-рилизинг-гормоном: повышение Лг более 6 Ед/л на фоне стимуляции свидетельствует в пользу гонадотропин-зависимого ППР [60, 61, 68-74].

В инструкции к применению \#трипторелина** 0,1 мг и \#бусерелина* 150 мкг/доза нет указания на применение в рамках диагностических тестов при обследовании по поводу нарушений полового развития. Однако данные препараты применяются с указанной выше целью вне зарегистрированных показаний на основании результатов эффективности и безопасности по международным данным и клиническим опытом в ФГБУ «НМИЦ эндокринологии» [75-80].

Ранее пороговым значением ЛГ на пробе с аналогом ГнРГ, подтверждающим центральное ППР, считалось значение 10 Ед/л, однако в соответствии с данными международных исследований и клиническим опытом в ФГБУ «НМИЦ эндокринологии», рекомендовано снизить пороговое значение до 6 Ед/л [60, 61, 68-74].

Отсутствие повышения Лг свидетельствует в пользу гонадотропин-независимого ППР.

Превышение уровня ФСГ над уровнем ЛГ свидетельствует в пользу изолированного телархе. Исследование уровня общего тестостерона крови у мальчиков,

Таблица 2. Варианты проведения пробы с препаратом гонадотропин-рилизинг-гормона

\begin{tabular}{|c|c|c|c|c|}
\hline Препарат & Доза & Способ введения & $\begin{array}{c}\text { Время забора } \\
\text { крови }\end{array}$ & $\begin{array}{c}\text { Определяемые } \\
\text { гормоны }\end{array}$ \\
\hline \multirow[t]{2}{*}{ \#Бусерелин ${ }^{* *}$} & 300 мкг & Интраназально & $0,14,4$ ч & \\
\hline & & & & лГ и ФСГ \\
\hline \#Трипторелин** & 100 мкг & $\Pi / \mathrm{K}$ & $0,1 ч, 4$ ч & \\
\hline
\end{tabular}


исследование уровня общего эстрадиола у девочек позволяет подтвердить диагноз ППР при выраженной прогрессии полового развития и не является информативным на ранних стадиях истинного преждевременного полового развития.

Значительное превышение уровня общего эстрадиола крови на фоне допубертатных значений гонадотропных гормонов является критерием эстроген-секретирующих кист и опухолей яичников [17, 19, 20, 44-46, 81].

Значительное превышение уровня андрогенов крови на фоне допубертатных значений гонадотропных гормонов является критерием гиперфункции яичек, опухолей яичек или надпочечников $[11,13]$.

Рекомендуется у мальчиков с ППР обязательное определение исследование уровня 17-гидроксипрогестерона (17ОНР) в крови для исключения врожденной дисфункции коры надпочечников (ВДКН), альфа-фетопротеина, бета-субъединицы хориониче-

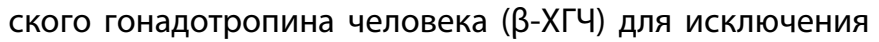
герминогенных опухолей, исследование уровня дегидроэпиандростерона (ДГЭА) крови и/или дегидроэпиандростерона сульфата крови (ДГЭА-С) для исключения андроген-продуцирующих опухолей надпочечников [82-87]. УДД - 4, УУР - С.

- Рекомендуется у девочек с преждевременным адренархе обязательное исследование уровня 17ОНР и ДГЭА/ДГЭА-С для исключения ВДКН; андростендиона крови, ДГЭА/ДГЭА-С крови и общего тестостерона крови для исключения андроген-продуцирующих опухолей яичников или надпочечников $[82,84,88,89]$. УДД - 4, УУР - C.

\section{Комментарии.}

- При идиопатическом преждевременном адренархе уровень ДГЭА-С (ДГЭА-С менее вариабельный показатель по сравнению с ДГЭА) соответствует 2 стадии по Tanner (40-135 мкг/дл или 1,1-3,7 мкмоль/л), тогда как при андроген-продуцирующих опухолях надпочечников ДГЭА-С превышает 500 мкг/дл (15 мкмоль/л). - Уровень 17ОНР выше 15 нмоль/л (5нг/мл) с высокой вероятностью свидетельствует о неклассической форме дефицита 21-гидроксилазы. В сомнительных случаях (уровень 17ОНР 6-15 нмоль/л) рекомендовано дообследование (изложены в протоколах по ВДКН).

2.4. Инструментальные диагностические исследования.

- Рекомендуется девочкам младше 8 лет с клиническими признаками ППР и мальчикам младше 9 лет с клиническими признаками ППР проведение рентгенограммы кистей рук для оценки костного возраста [90-99]. УДД - 3, уУР - С.

\section{Комментарии.}

- Определение костного возраста проводится на основании рентгенографии кистей (левой кисти для правшей) - опережение костного возраста более чем на 2 года от паспортного является критерием ППР $[90,95,96,98,99]$.

- При определении костного возраста рекомендуется использовать атлас Greulich-Pale, или систему TannerWhitehouse, или метод Бухмана $[90,92,93,96]$.

- Рекомендуется проведение МРТ головного мозга при доказанном гонадотропин-зависимом харак- тере ППР девочкам с манифестацией ППР в возрасте 6 лет и младше и мальчикам с манифестацией ППР до 9 лет с целью исключения объемных образований гипоталамо-селлярной области [3, 32, 34, 100, 101]. УДД - 4, УУР — С.

\section{Комментарии.}

- Обязательно проведение МРТ у всех мальчиков с гонадотропин-зависимым ППР и у девочек младше 6 лет.

- Девочкам с дебютом гонадотропин-зависимого ППР в промежутке от 6 до 8 лет МРТ проводится при наличии неврологической симптоматики и/или признаков гипопитуитаризма [3, 102].

- Поскольку гонадотропин-зависимое ППР не связано с аденомами гипофиза, нет необходимости в контрастном усилении при проведении МРТ.

- $\quad$ Рекомендуется проведение УЗИ мошонки мальчикам с клиническими признаками ППР для оценки соответствия возрасту объема яичек, исключения объемных образований яичек мальчикам с клиническими признаками ППР [103-106]. УДД - 4, УУР - С.

- Рекомендуется проведение УзИ органов малого таза девочкам с клиническими признаками ППР для оценки соответствия возрасту размеров матки и объема яичников, исключения объемных образований яичников [3, 44-46]. УДД - 3, УУР - В.

Рекомендуется проведение визуализирующих методов исследования надпочечников (УЗИ надпочечников и/или МРТ надпочечников, или по показаниям МСКТ надпочечников) для исключения объемных образований и гиперплазии надпочечников детям с адренархе и/или повышенным уровнем ДГЭА/ДГЭА-С. [84-88, 106] УДД - 4, УУР - С.

\section{Комментарии:}

наличие эхо-признаков фолликула более 1 см в диаметре у девочки препубертатного возраста определяется как киста яичника;

при проведении УЗИ органов малого таза в рамках диагностики ППР следует оценивать соответствие размеров матки и объема яичников возрасту. Объем яичников рассчитывается по формуле: длина $($ см) $\times$ ширина $($ см) $\times$ высота $($ см $) \times 0,5233$. При центральном ППР у девочек отмечаются бО́льшие размеры матки и объем яичников (по сравнению с препубертатным контролем и девочками с изолированным телархе) [107];

высокоспецифичным, но малочувствительным признаком гонадотропин-зависимого преждевременного полового развития является наличие эхо-признаков эндометрия [43];

- у девочек на стадии манифестации гонадотропин-зависимого ППР матка и яичники могут быть еще допубертатных размеров, в связи с чем при дифференциальной диагностике между гонадотропин-зависимым преждевременным половым развитием и изолированным телархе проведение УЗИ матки и яичников у девочек может использоваться только как вспомогательный метод [43, 108, 109].

Рекомендуется проведение МРТ головного мозга, УЗИ печени, КТ средостения мальчикам с ППР и повышенным ХГЧ с целью поиска герминативно-клеточных опухолей [39, 109-113]. УДД - 5, УУР - С. 


\section{5 Иные диагностические исследования}

- Детям с диагнозом синдром МакКьюна-Олбрайта-Брайцева рекомендуется обследование для исключения других компонентов заболевания [114]. УДД - 5, УУР - С.

Комментарии. Пациентам с синдромом МОБ необходимо регулярное обследование с целью скрининга компонентов заболевания:

- УзИ щитовидной железы для исключения узлов.

- Исследование уровня свободного тироксина (св.Т4) крови, исследование уровня тиреотропного гормона (ТТГ) в крови для исключения тиреоидной автономии. Исследование уровня соматотропного гормона в крови, исследование уровня пролактина крови, исследование уровня инсулиноподобного ростового фактора 1 в крови (ИФР-1) для исключения акромегалии и гиперпролактинемии

- Оценка уровня тубулярной реабсорбции фосфатов для исключения гипофосфатемического рахита.

- Исключение синдрома Кушинга у детей первых лет жизни (исследование уровня адренокортикотропного гормона в крови (АКТГ), исследование уровня общего кортизола крови, исследование уровня свободного кортизола в моче мочи, исследование уровня дегидроэпиандростерона сульфата в крови (ДГЭА-С).

- Проведение глюкозотолерантного теста с определением СТГ (по показаниям - при повышенном уровне СТГ и/или ИФР-1).

- МРТ головного мозга для исключения аденомы гипофиза (по показаниям - при отсутствии подавления СТГ на пробе или при гиперпролактинемии).

- Сцинтиграфия костей всего тела для уточнения распространенности фиброзной дисплазии (после 5-6 лет) и/или рентгенография в прямой проекции нижних конечностей для исключения очагов фиброзной дисплазии, угрожаемых патологическими переломами и/или требующих оперативного лечения.

- МСКТ головы (по показаниям - для уточнения очагов фиброзной дисплазии черепа).

- Офтальмоскопия (по показаниям - для исключения атрофии зрительных нервов при наличии очагов фиброзной дисплазии черепа).

- Детям с ППР вследствие объемных образований головного мозга, локализующихся в хиазмально-селлярной области, и детям с ППР, перенесшим облучение хиазмально-селлярной области рекомендуется обследование для исключения гипопитуитаризма [114-119]. УДД - 4, УУР - С.

\section{3. ЛЕЧЕНИЕ, ВКЛЮЧАЯ МЕДИКАМЕНТОЗНУЮ И НЕМЕДИКАМЕНТОЗНУЮ ТЕРАПИИ, ДИЕТОТЕРАПИЮ, ОБЕЗБОЛИВАНИЕ, МЕДИЦИНСКИЕ ПОКАЗАНИЯ И ПРОТИВОПОКАЗАНИЯ К ПРИМЕНЕНИЮ МЕТОДОВ ЛЕЧЕНИЯ}

\section{1. Консервативное лечение.}

Терапевтическая тактика определяется этиологическим вариантом ППР. Целью лечения ППР является торможение прогрессирования костного возраста и препятствие прогрессии полового развития, что позволит адаптировать пациентов с психологической и социальной точек зрения.
- $\quad$ Рекомендуется назначение пролонгированных аналогов гонадотропин-рилизинг гормона при установленном диагнозе гонадотропин-зависимого преждевременного полового развития у девочек до 6 лет и у мальчиков до 9 лет $[3,120]$ УДД - 5, УУР - С.

- Рекомендуется при установленном диагнозе гонадотропин-зависимого преждевременного полового развития у девочек с 6 до 8 лет индивидуальное решение вопроса о назначении пролонгированных аналогов гонадотропин-рилизинг гормона $[3,121]$ УДД - 5, УУР - С.

\section{Комментарии.}

- Возможно назначение пролонгированных аналогов ГнРГ после 8 лет у девочек и 9 лет у мальчиков при наличии приобретенного СТГ дефицита на фоне опухолей ЦНС в том случае, если есть возможность терапии препаратами гормона роста (Н01AC: Соматропин Гормоны передней доли гипофиза и их аналоги) для улучшения ростового прогноза.

- Пациентов с гонадотропин-зависимой формой ППР следует включать в Федеральный регистр лиц, страдающих жизнеугрожающими и хроническими прогрессирующими редкими (орфанными) заболеваниями, приводящими к сокращению продолжительности жизни граждан или их инвалидности» [121].

В группе девочек с гонадотропин-зависимым преждевременным половым развитием в возрасте от 6 до 8 лет достоверного улучшения ростового прогноза не получено. Вопрос о назначении терапии в данной группе пациентов решается индивидуально с учетом психологической составляющей [122].

- В России на сегодняшний день зарегистрированы для использования у детей с гонадотропин-зависимым преждевременным половым развитием два препарата из группы пролонгированных аналогов ГнРГ для ежемесячных инъекций: \#трипторелин ${ }^{* *} 3,75$ мг и \#лейпрорелин ${ }^{* *}$ 3,75 мг. Оба препарата имеют схожую эффективность и безопасность. Препараты трипторелин $^{* *}$ или лейпрорелин ${ }^{* *}$ назначаются в/м 1 раз в 28 дней в стартовой дозе 3,75 мг вне зависимости от веса ребенка [123-127].

- В России имеются пролонгированные аналогиГнРГболее длительного действия - трипторелин ${ }^{* *} 11,25$ мг и \#лейпрорелин ${ }^{* *}$ 11,25 мг, которые назначаются в/м с частотой 1 раз в 12 нед. Эти препараты используются в Европе и США в лечении детей с преждевременным половым развитием с доказанной эффективностью и безопасностью $[3,120]$.

- Детям, получающим терапию пролонгированными аналогами ГнРГ по поводу ППР, рекомендуется обязательное соблюдение условий терапии пролонгированными аналогами ГнРГ: непрерывность терапии, ведение календаря и соблюдение режима инъекций $[117,128]$. УДД - 5, Уур - С.

- Детям, получающим терапию пролонгированными аналогами ГнРГ по поводу ППР, рекомендуется регулярная оценка эффективности проводимой терапии [3, 120]. УДД - 5, УУР - С.

Комментарии. Оценка эффективности проводится не раньше, чем через 3 мес от начала лечения, затем не реже 1 раза в год. Оценка результата лечения проводится только по совокупности клинических и лабораторных показателей [3, 129]. 
Протокол ведения пациентов, получающих терапию пролонгированными аналогами ГнРГ:

Оценка полового развития - 1 раз/6 мес.

Антропометрия - 1 раз/6 мес.

- Рентгенография кистей (1 раз/год), при высоких темпах роста и прогрессии полового развития 1 раз/6 мес.

- Исследование уровня гормонов крови: ЛГ (целевой уровень менее 0,5 Ед/л), общий тестостерон (целевое значение менее 1 нмоль/л) или общий эстрадиол (целевое значение менее 70 пмоль/л) - 1 раз/6 мес. (анализы проводятся за 1-3 дня до очередной инъекции препарата).

- УзИ органов малого таза у девочек - 1 раз/6 мес. в первый год лечения, далее по показаниям.

\section{Критерии эффективности терапии.}

1. Скорость роста (снижение до возрастной нормы).

2. Отсутствие прогрессии полового развития или регресс вторичных половых признаков.

3. Прогрессия костного возраста не более чем на 1 год за 1 год (проводится 1 раз в год, при необходимости через 6 мес).

4. Базальный уровень ЛГ и стероидных гормонов крови (общего тестостерона для мальчиков, общего эстрадиола для девочек) может служить критерием эффективности только в том случае, если до начала лечения имелся повышенный уровень этих гормонов; умеренно повышенный уровень ФСГ не является признаком отсутствия эффекта от терапии.

В сомнительных случаях через 6 месяцев от начала терапии (при неполном соответствии критериям эффективности терапии) проводится проба с аналогом ГнРГ (за 1 день до очередной инъекции аналога ГнРГ), критерием эффективности лечения является отсутствие выброса ЛГ на пробе более 4 Ед/л [130-137]. Считается доказанным отсутствие негативного влияния длительной терапии пролонгированными аналогами ГнРГ на набор веса и снижение минеральной плотности костной ткани у детей с ППР [129].

В настоящее время не существует четких критериев, определяющих сроки отмены терапии, каждый случай рассматривается индивидуально, принимая во внимание следующие критерии [3]:

- Достижение пубертатного возраста (девочки 10-12 лет, мальчики 11-13 лет).

- Достижение костного возраста (девочки 12-13 лет, мальчики 14 лет).

- Снижение скорости роста менее 2 SD для данного костного возраста.

- Достижение роста, соответствующего костному возрасту (конечный прогнозируемый рост, близкий к целевому).

- Психологическая готовность ребенка и родителей.

- Рекомендуется коррекция терапии детям, получающим терапию пролонгированными аналогами ГнРГ по поводу ППР, в случае недостаточного подавления гонадотропинов на фоне лечения (рекомендуется увеличение дозы препарата (трипторелина или лейпрорелина) с 3,75 мг/28 дней до 7,5 мг/28 дней) [131, 137]. УДД - 3, Уур - B.

\section{Лечение гонадотропин-независимого ППР.}

1. Детям с ППР вследствие врожденной дисфункции коры надпочечников рекомендуется проводить (обследование и лечение) в соответствии с клиническими рекомендациями по ВДКН [138]. УДД - 5, Уур - C.

2. Детям с гонадотропин-независимыми формами ППР вопрос о назначении лечения рекомендуется решать в каждом случае индивидуально в специализированных центрах $[11,139]$. УДД - 5, уур - С.

Комментарии. В настоящее время используются ингибиторы ароматазы 3 поколения - \#летрозол, \#анастрозол ${ }^{* *}$; антиэстрогены — \#тамоксифен ${ }^{* *}$ или \#фулве-

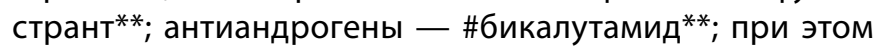
не существует единых общепринятых схем и доз терапии гонадотропин-независимых форм преждевременного полового развития данными препаратами, но по данным мировой практики при лечении гонадотропин-независимого преждевременного полового развития \#летрозол используют в дозе 2,5 мг ежедневно перорально, \#анастрозол $^{* *} 1$ мг в день ежедневно, перорально, \#тамоксифен $^{* *}$ в дозе 10-20 мг в день ежедневно перорально, \#фулвестрант ${ }^{* *} 4$ мг/кг внутримышечно каждые 28 дней, \#бикалутамид** в дозах от 12,5 до 100 мг/день по данным разных источников [140-148].

Диагноз «Преждевременное половое развитие» не значится в показаниях к применению ни у одного из вышеперечисленных препаратов, поэтому при назначении лекарственного препарата вне зарегистрированных показаний рекомендуется обязательное подробное информирование родителей с подписанием ими информированного согласия и инициация или согласование терапии в специализированных научных центрах с проведением врачебной комиссии [139].

Лечение гонадотропин-независимого преждевременного полового развития при синдроме МОБ у девочек назначается в случае опережения костного возраста на 2 года и более, частых эпизодов кровянистых выделений. В настоящее время рекомендуется назначение ингибитора ароматазы 3 поколения - \#летрозол ${ }^{* *} 2,5$ мг $\times$ 1 раз в день. При неэффективности данной терапии - сочетание или замена на антиэстрогены - \#тамоксифен ${ }^{* *}$ 10 мг × 1 раз в день или \#фулвестрант** 4 мг/кг/месяц [114, 140-145].

Для лечения гонадотропин-независимого преждевременного полового развития при синдроме МОБ у мальчиков, сопровождающегося опережением костного возраста на 2 года и более, и для лечения тестотоксикоза в настоящее время рекомендуется назначение ингибитора ароматазы 3 поколения \#анастрозол ${ }^{* *} 1$ мг × 1 раз в день перорально сочетании с антиандрогенами \#бикалутамидом** в дозах от 12,5 до 100 мг/день [146-148].

Возможна трансформация гонадотропин-независимого ППР в гонадотропин-зависимое при костном возрасте, близком к пубертатному. Для диагностики данного состояния используется стандартная проба с аналогом ГнРГ. При доказанном гонадотропин-зависимом характере ППР у детей с первично периферическим ППР возможно применение пролонгированных аналогов ГнРГ $[11,149,150]$. УДД - 3, УУР - В. 
3.2. Хирургическое лечение.

- Хирургическое или лучевое лечение объемных образований головного мозга у детей с ППР рекомендуется проводить только по показаниям, определяемым врачом-нейрохирургом: гонадотропин-зависимое преждевременное половое развитие хорошо поддается терапии пролонгированными аналогами ГнРГ вне зависимости от нозологического варианта и не является показанием к хирургическому лечению $[125,126,129$, 130, 131, 151]. УДД - 5, Уур - С.

- Детям с ППР, обусловленным объемными образованиями надпочечников и гонад, рекомендовано хирургическое лечение (см. протокол ведения пациентов с опухолями надпочечников и гонад) $[152,153,154,155]$. УДД - 3, уУР - В.

- Не рекомендуется хирургическое удаление кист яичников девочкам при синдроме МОБ, учитывая потенциальный негативный эффект на фертильность и высокую вероятность рецидива кист в оставшейся ткани яичника. Исключение составляют случаи длительной персистенции кист и подозрение на новообразование [114]. УДД - 5, УУР - С.

\section{3. Иное лечение.}

- Детям с синдромом МакКьюна-Олбрайта-Брайцева рекомендовано проводить терапию каждого компонента заболевания в зависимости от представленности проявлений заболевания в каждом конкретном случае [114]. УДД - 5, УУР - С.

Комментарии. Мальчики с ХГЧ-секретирующими герминативно-клеточными опухолями получают лечение у врачей-онкологов по соответствующим протоколам $[156,157]$. УДД - 3, УУР - В.

\section{4. МЕДИЦИНСКАЯ РЕАБИЛИТАЦИЯ, МЕДИЦИНСКИЕ ПОКАЗАНИЯ И ПРОТИВОПОКАЗАНИЯ К ПРИМЕНЕНИЮ МЕТОДОВ РЕАБИЛИТАЦИИ}

При отсутствии своевременного назначения лечения при преждевременном половом развитии отмечается ускоренное закрытие зон роста и негативный прогноз конечного роста, что может потребовать психологической поддержки для адаптации пациента.

\section{5. ПРОФИЛАКТИКА И ДИСПАНСЕРНОЕ НАБЛЮДЕНИЕ, МЕДИЦИНСКИЕ ПОКАЗАНИЯ И ПРОТИВОПОКАЗАНИЯ К ПРИМЕНЕНИЮ МЕТОДОВ ПРОФИЛАКТИКИ}

- Всем детям рекомендуется для раннего выявления признаков преждевременного полового развития и своевременного назначения лечения проводить антропометрию (скорость роста за предшествующие 6-12 мес), оценку полового развития на основании шкалы Tanner [4, 47]. УДД - 3, УУР - В.

- Детям с преждевременным половым развитием рекомендуется проводить регулярное обследование с оценкой параметров эффективности на фоне проводимого лечения [3, 117]. УДД - 5, УУР - С.

\section{6. ОРГАНИЗАЦИЯ ОКАЗАНИЯ МЕДИЦИНСКОЙ помощи.}

Показания для госпитализации в медицинскую организацию.

- Плановая госпитализация в специализированный стационар (дневной стационар) детей с подозрением на ППР или для проведения динамического обследования показана при невозможности проведения обследования в полном объеме амбулаторно. Плановая госпитализация в специализированный стационар или дневной стационар детей с установленным диагнозом ППР показана при необходимости решения вопроса о назначении препаратов вне зарегистрированных показаний.

- Экстренная госпитализация детей в стационар с подозрением на ППР при наличии неврологической симптоматики, симптомах «острого живота» на фоне объёмных образований гонад или надпочечников.

Показания к выписке пациента из медицинской организации:

- После уточнения диагноза и определения дальнейшей тактики ведения.

- Маршрутизация пациента в специализированную медицинскую организацию при отсутствии возможности уточнения диагноза и определения тактики ведения в условиях госпитализации в текущей медицинской организации.

\section{7. ДОПОЛНИТЕЛЬНАЯ ИНФОРМАЦИЯ, ВЛИЯЮЩАЯ НА ТЕЧЕНИЕ И ИСХОД ЗАБОЛЕВАНИЯ.}

На течение и исход заболевания влияют сроки манифестации заболевания, сроки установления диагноза, особенности основного заболевания, на фоне которого развилось преждевременного половое развитие

\section{ДОПОЛНИТЕЛЬНАЯ ИНФОРМАЦИЯ}

Порядок обновления клинических рекомендаций. Механизм обновления клинических рекомендаций предусматривает их систематическую актуализацию - не реже чем 1 раз в 3 года, а также при появлении новых данных с позиции доказательной медицины по вопросам диагностики, лечения, профилактики и реабилитации конкретных заболеваний, наличии обоснованных дополнений/замечаний к ранее утвержденным KР, но не чаще 1 раза в 6 мес.

Источники финансирования. Работа выполнена по инициативе авторов без привлечения финансирования.

Конфликт интересов. Авторы декларируют отсутствие явных и потенциальных конфликтов интересов, связанных с содержанием и публикацией настоящей статьи.

Участие авторов. Все авторы одобрили финальную версию статьи перед публикацией, выразили согласие нести ответственность за все аспекты работы, подразумевающую надлежащее изучение и решение вопросов, связанных с точностью или добросовестностью любой части работы. 


\section{Б1. АЛГОРИТМ ДИАГНОСТИКИ ППР У ДЕВОЧЕК С ПРЕЖДЕВРЕМЕННЫМ УВЕЛИЧЕНИЕМ МОЛОЧНЫХ ЖЕЛЕЗ}

Таблица 3. Критерии оценки качества медицинской помощи

Критерии качества

Уровень
достоверности
доказательств

Уровень

убедительности

доказательств

рекомендаций

1. Выполнены измерение роста и оценка SDS роста

удд - 3, уур - в. удД - 3, уур - в

2. Проведен подсчет скорости роста за предшествующие 6-12 мес

(при наличии данных роста)

удД -3, ууР - В $\quad$ удД -3, уур - В

3. Выполнена клиническая оценка полового развития

на основании шкалы Таннер

удд - 3, уур - в $\quad$ удд - 3, уур - в

4. Выполнена рентгенография кистей с оценкой костного возраста

4. при диагностике ППР

удд - 3 уур - $\quad$ удд - 3, уур -

5. Выполнено исследование уровня Лг крови при диагностике ПпР УДД - 3, уУР - В УдД - 3, УУР - В

6. У детей с преждевременным адренархе выполнено определение

6. крови 17ОНР, ДГЭА/ДГЭА-С при диагностике ППР

удД - 3, уур - В УДД - 3, уур - В

Мальчикам с гонадотропин-зависимым ППР и девочкам

7. с гонадотропин-зависимым ППР младше 6 лет выполнено МРТ $\quad$ УДД - 4, УУР - C УДД - 4, УУР - С головного мозга при диагностике ППР

8. Выполнено УЗИ органов малого таза у девочек с ППР и УЗИ

мошонки у мальчиков с ППР при диагностике ППР

удд - 4, уур - $\quad$ удд -4, уур $-\mathrm{C}$

Проведены визуализирующие методы исследования

9. надпочечников (УЗИ/МРТ/МСКТ) детям с адренархе

9. и/или с повышенным уровнем ДГЭА и/или ДГЭА-С

удД - 4, уур - $~ \quad$ удД - 4, уур -

при диагностике ППР

Девочкам младше 6 лет и мальчикам младше 9 лет назначен

10. аналог Гн-РГ пролонгированного действия при доказанном центральном ППР

удд - 5, уур - $\quad$ удд -5, уур $-\mathrm{C}$

Детям с центральным ППР, получающим лечение аналогом

11. Гн-РГ пролонгированного действия, проводится регулярное

11. (1 раз в 6-12 мес.) обследование для оценки эффективности

удД - 5, уур - $\quad$ удд -5, уур $-\mathrm{C}$ терапии

Детям с центральным ППР, получающим лечение аналогом Гн-РГ

12. пролонгированного действия, при выявлении неэффективности проводимого лечения, проведена коррекция терапии. 
Б1. АЛГОРИТМ ДИАГНОСТИКИ ППР У ДЕВОЧЕК С ПРЕЖДЕВРЕМЕННЫМ УВЕЛИЧЕНИЕМ МОЛОЧНЫХ ЖЕЛЕЗ (ПРОДОЛЖЕНИе)

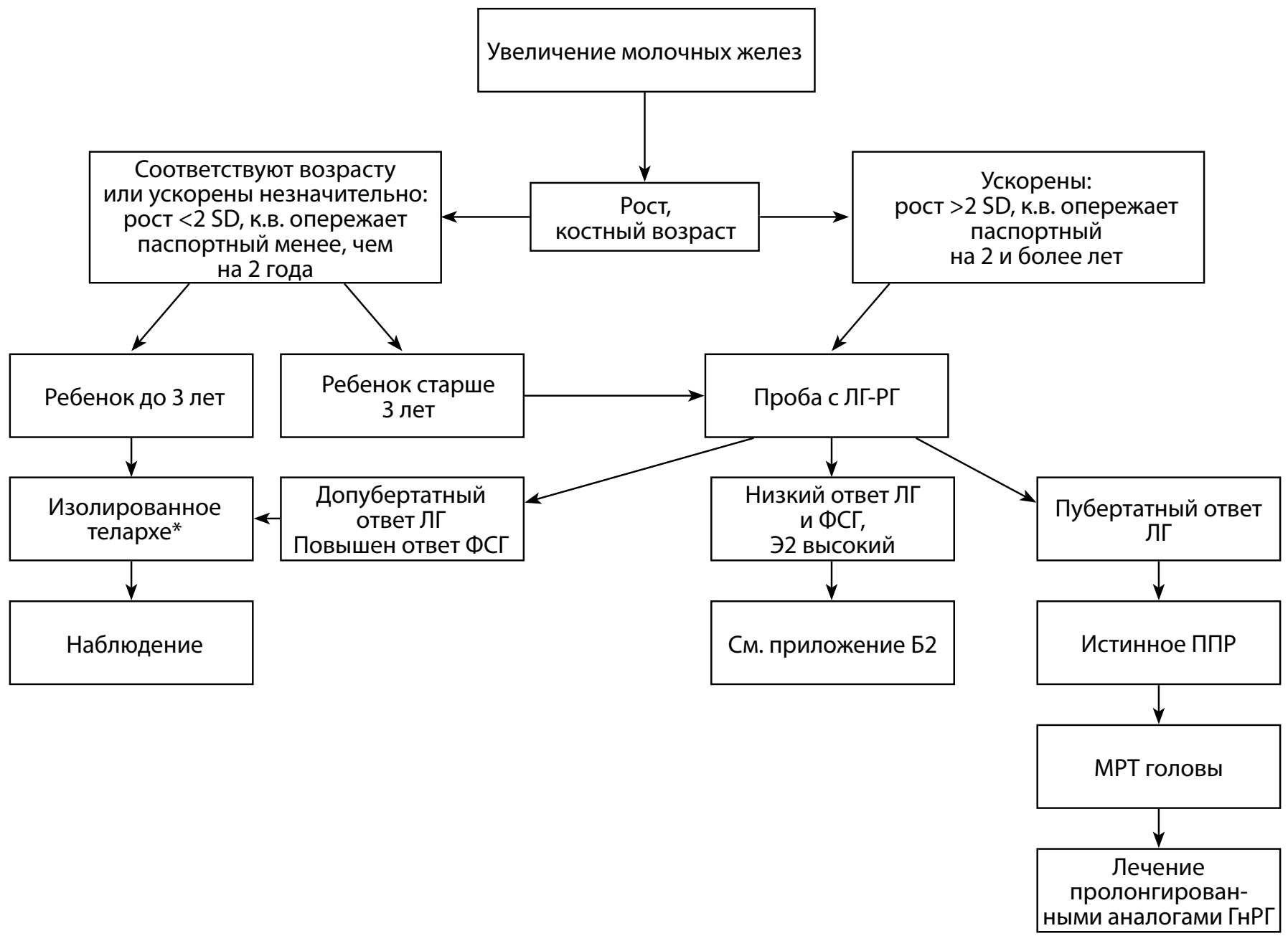

\section{Б2. АЛГОРИТМ ДИАГНОСТИКИ ППР У ДЕВОЧЕК С ПРЕЖДЕВРЕМЕННЫМ УВЕЛИЧЕНИЕМ МОЛОЧНЫХ ЖЕЛЕЗ И МЕНСТРУАЛОПОДОБНЫМИ ВЫДЕЛЕНИЯМИ}

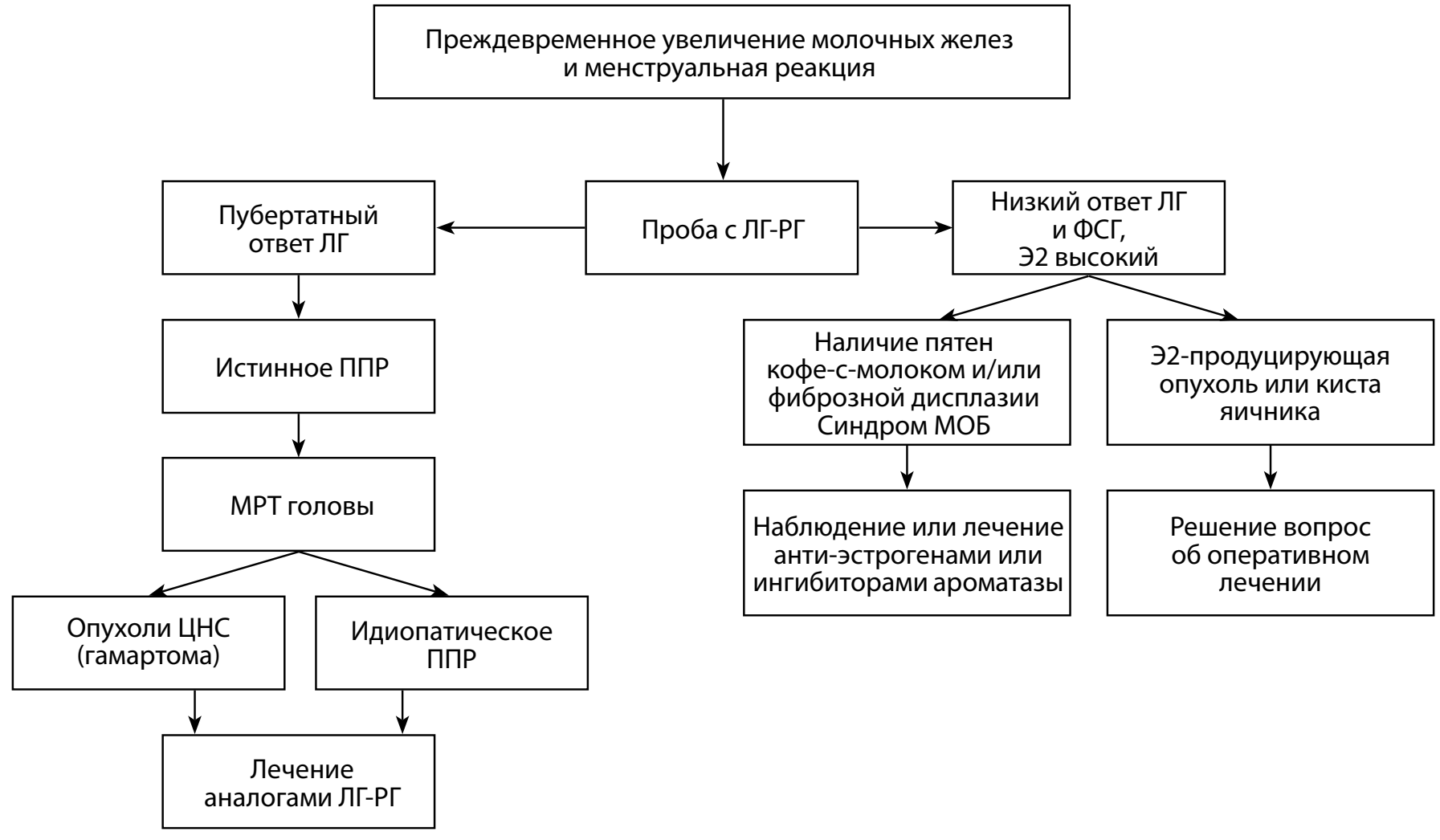




\section{БЗ. АЛГОРИТМ ДИАГНОСТИКИ ППР У ДЕВОЧЕК С ПРЕЖДЕВРЕМЕННЫМ ИЗОЛИРОВАННЫМ АДРЕНАРХЕ}

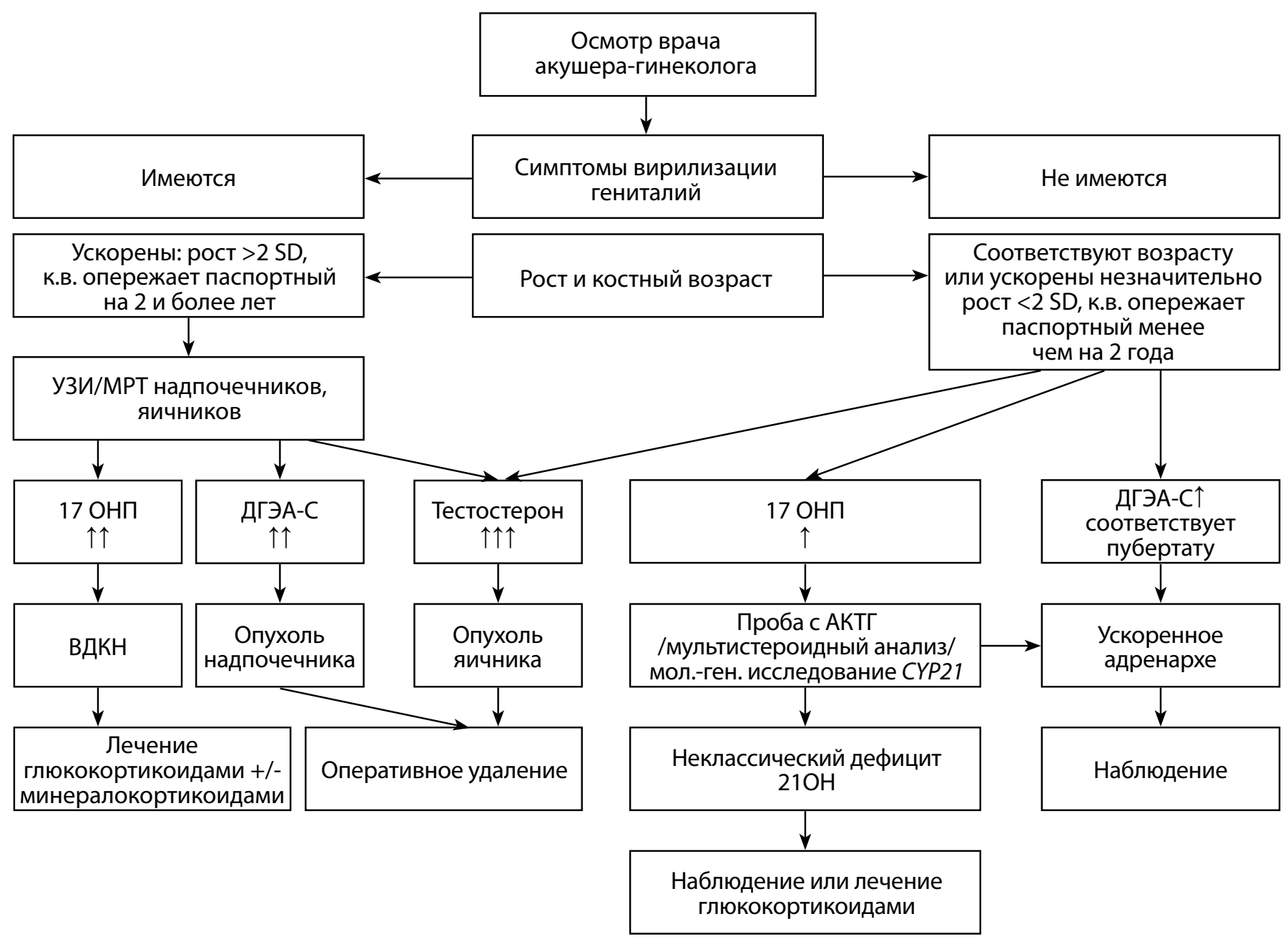




\section{Б4. АЛГОРИТМ ДИАГНОСТИКИ ППР У МАЛЬЧИКОВ}






\section{СПИСОК ЛИТЕРАТУРЫ | REFERENCES}

1. Дедов И.И., Семичева Т.В., Петеркова В.А. Половое развитие: норма и патология. - М.: Колор Ит Студио; 2002. - С. 67-69. [Dedov II, Semicheva TV, Peterkova VA. Polovoe razvitie: norma ipatologiya. Moscow: Kolor It Studio; 2002. P. 67-69. (In Russ.)].

2. Дедов И.И., Петеркова В.А. Руководство по детской эндокринологии. М.: Универсум паблишинг; 2006. [Dedov II, Peterkova VA. Rukovodstvo po detskoi endokrinologii. Moscow: Universum pablishing; 2006. (In Russ.)].

3. Carel J-C, Eugster EA, Rogol A, et al. Consensus Statement on the Use of Gonadotropin-Releasing Hormone Analogs in Children. Pediatrics. 2009;123(4):e752-e762. doi: https://doi.org/10.1542/peds.2008-1783

4. Marshall WA, Tanner JM. Variations in the Pattern of Pubertal Changes in Boys. Arch Dis Child. 1970;45(239):13-23.

doi: https://doi.org/10.1136/adc.45.239.13

5. Chen M, Eugster EA. Central Precocious Puberty: Update on Diagnosis and Treatment. Pediatr Drugs. 2015;17(4):273-281. doi: https://doi.org/10.1007/s40272-015-0130-8

6. Partsch C-J, Japing I, Siebert R, et al. Central precocious puberty in girls with Williams syndrome. J Pediatr. 2002;141(3):441-444. doi: https://doi.org/10.1067/mpd.2002.127280

7. Temple IK, Cockwell A, Hassold T, et al. Maternal uniparental disomy for chromosome 14. J Med Genet. 1991;28(8):511-514. doi: https://doi.org/10.1136/jmg.28.8.511

8. Ioannides Y, Lokulo-Sodipe K, Mackay DJ, et al. Temple syndrome: improving the recognition of an underdiagnosed chromosome 14 imprinting disorder: an analysis of 51 published cases. J Med Genet. 2014;51 (8):495-501. doi: https://doi.org/10.1136/jmedgenet-2014-102396

9. Wakeling EL, Brioude F, Lokulo-Sodipe O, et al. Diagnosis and management of Silver-Russell syndrome: first internationa consensus statement. Nat Rev Endocrinol. 2017;13(2):105-124. doi: https://doi.org/10.1038/nrendo.2016.138

10. Berberoğlu M. Precocious puberty and normal variant puberty: definition, etiology, diagnosis and current management. J Clin Res Pediatr Endocrinol. 2009;1 (4):164-174. doi: https://doi.org/10.4274/jcrpe.v1i4.3

11. Haddad NG, Eugster EA. Peripheral precocious puberty including congenital adrenal hyperplasia: causes, consequences, management and outcomes. Best Pract Res Clin Endocrinol Metab. 2019;33(3):101273. doi: https://doi.org/10.1016/j.beem.2019.04.007

12. Rousseau-Merck MF, Misrahi M, Atger M, et al. Localization of the human luteinizing hormone/choriogonadotropin receptor gene (LHCGR) to chromosome 2p21. Cytogenet Genome Res. 1990;54(1-2):77-79. doi: https://doi.org/10.1159/000132962

13. Shenker A, Laue L, Kosugi S, et al. A constitutively activating mutation of the luteinizing hormone receptor in familial male precocious puberty. Nature. 1993;365(6447):652-654. doi: https://doi.org/10.1038/365652a0

14. Weinstein LS, Shenker A, Gejman PV., et al. Activating Mutations of the Stimulatory G Protein in the McCuneAlbright Syndrome. N Engl J Med. 1991;325(24):1688-1695. doi: https://doi.org/10.1056/NEJM199112123252403

15. Svoboda $\mathrm{P}$, et al. Biochemistry of transmembrane signaling mediated by trimeric G proteins. Physiol. Res. 2004;53(1):141-152.

16. Dumitrescu CE, Collins MT. McCune-Albright syndrome. Orphanet J Rare Dis. 2008;3(1):12. doi: https://doi.org/10.1186/1750-1172-3-12

17. Collins MT, Singer FR, Eugster E. McCune-Albright syndrome and the extraskeletal manifestations of fibrous dysplasia. Orphanet J Rare Dis. 2012;7(S1):S4. doi: https://doi.org/10.1186/1750-1172-7-S1-S4

18. Coutant R, Lumbroso S, Rey R, et al. Macroorchidism due to Autonomous Hyperfunction of Sertoli Cells and G s a Gene Mutation: An Unusual Expression of McCune-Albright Syndrome in a Prepubertal Boy. J Clin Endocrino/ Metab. 2001;86(4):1778-1781. doi: https://doi.org/10.1210/jcem.86.4.7391

19. Sinnecker G, Willig RP, Stahnke N, Braendle W. Precocious pseudopuberty associated with multiple ovarian follicular cysts and low plasma oestradiol concentrations. Eur J Pediatr. 1989;148(7):600-602. doi: https://doi.org/10.1007/BF00441508

20. Pienkowski C, Cartault A, Carfagna L, et al. Ovarian cysts in prepubertal girls. Endocr Dev. 2012;22:101-111. doi: https://doi.org/10.1159/000326627

21. Dehner LP. Gonadal and extragonadal germ cell neoplasia of childhood. Hum Pathol. 1983;14(6):493-511. doi: https://doi.org/10.1016/50046-8177(83)80004-5
22. McLachlan RI, O'Donnell L, Meachem SJ, et al. Identification of specific sites of hormonal regulation in spermatogenesis in rats, monkeys, and man. Recent Prog Horm Res. 2002;57:149-179. doi: https://doi.org/10.1210/rp.57.1.149

23. Kubo O, Yamasaki N, Kamijo Y, et al. Human chorionic gonadotropin produced by ectopic pinealoma in a girl with precocious puberty. J Neurosurg. 1977;47(1):101-105. doi: https://doi.org/10.3171/jns.1977.47.1.0101

24. Kitanaka C, Matsutani M, Sora S, et al. Precocious puberty in a girl with an hCG-secreting suprasellar immature teratoma. J Neurosurg. 1994;81 (4):601-604. doi: https://doi.org/10.3171/jns.1994.81.4.0601

25. Anasti JN, Flack MR, Froehlich J, et al. A potential novel mechanism for precocious puberty in juvenile hypothyroidism. J Clin Endocrinol Metab. 1995;80(1):276-279. doi: https://doi.org/10.1210/jcem.80.1.7829625

26. Безлепкина О.Б., Семичева Т.В., Яровая И.С. Синдром Van Wyk-Grumbach (обзор литературы с описанием случаев) // Проблемы эндокринологии. — 1994. - Т. 40. — №4. - С. 35-38. [Bezlepkina OB, Semicheva TV, Yarovaya IS. Van Wyk-Grumbach syndrome in children (Review of literature with descriptions of clinical cases). Problems of Endocrinology. 1994;40(4):35-38. (In Russ.)]. doi: https://doi.org/10.14341/probl12143

27. Wyk JJ Van, Grumbach MM. Syndrome of precocious menstruation and galactorrhea in juvenile hypothyroidism: an example of hormonal overlap in pituitary feedback. J Pediatr. 1960;57(3):416-435 doi: https://doi.org/10.1016/S0022-3476(60)80250-8

28. Fuqua JS. Treatment and outcomes of precocious puberty: an update. J Clin Endocrinol Metab. 2013;98(6):2198-2207. doi: https://doi.org/10.1210/jc.2013-1024

29. de Vries L, Guz-Mark A, Lazar L, et al. Premature thelarche: age at presentation affects clinical course but not clinical characteristics or risk to progress to precocious puberty. J Pediatr. 2010;156(3):466-471. doi: https://doi.org/10.1016/j.jpeds.2009.09.071

30. Novello L, Speiser PW. Premature Adrenarche. Pediatr Ann. 2018;47(1):e7-e11. doi: https://doi.org/10.3928/19382359-20171214-04

31. Teilmann G. Prevalence and Incidence of Precocious Pubertal Development in Denmark: An Epidemiologic Study Based on National Registries. Pediatrics. 2005;116(6):1323-1328. doi: https://doi.org/10.1542/peds.2005-0012

32. Jung $H$, Ojeda SR. Pathogenesis of precocious puberty in hypothalamic hamartoma. Hormone Research. 2002;57(2):31-34. doi: https://doi.org/10.1159/000058097

33. Valdueza JM, Cristante L, Dammann O, et al. Hypothalamic Hamartomas. Neurosurgery. 1994;34(6):949-958. doi: https://doi.org/10.1227/00006123-199406000-00001

34. Gjikopulli A, Kollcaku L, Grimci L, et al. P32 - 2702: Hypothalamic hamartoma, gelastic epilepsy and precocious puberty. Eur J Paediatr Neurol. 2015;19:S103 doi: https://doi.org/10.1016/S1090-3798(15)30345-7

35. Stephen M, Zage P, Waguespack S. Gonadotropin-Dependent Precocious Puberty: Neoplastic Causes and Endocrine Considerations. Int J Pediatr Endocrinol. 2011;2011(1):184502. doi: https://doi.org/10.1155/2011/184502

36. Wood LD, Noë M, Hackeng W, et al. Patients with McCuneAlbright syndrome have a broad spectrum of abnormalities in the gastrointestinal tract and pancreas. Virchows Arch. 2017;470(4):391-400. doi: https://doi.org/10.1007/s00428-017-2086-2

37. Imel EA, Econs MJ. Fibrous dysplasia, phosphate wasting and fibroblast growth factor 23. Pediatr Endocrinol Rev PER. 2007;4(4):434-439.

38. Foster CM, Ross JL, Shawker T, et al. Absence of Pubertal Gonadotropin Secretion in Girls with McCune-Albright Syndrome. J Clin Endocrino/ Metab. 1984;58(6):1161-1165. doi: https://doi.org/10.1210/jcem-58-6-1161

39. Rivarola M, Belgorosky A, Mendilaharzu H, Vidal G. Precocious puberty in children with tumours of the suprasellar and pineal areas: Organic central precocious puberty. Acta Paediatr. 2007;90(7):751756. doi: https://doi.org/10.1111/j.1651-2227.2001.tb02800.x

40. Mills JL. Premature Thelarche. Am J Dis Child. 1981;135(8):743. doi: https://doi.org/10.1001/archpedi.1981.02130320057019

41. DeSalvo DJ, Mehra R, Vaidyanathan P, Kaplowitz PB. In children with premature adrenarche, bone age advancement by 2 or more years is common and generally benign. J Pediatr Endocrinol Metab. 2013;26(3-4):215-221. doi: https://doi.org/10.1515/jpem-2012-0283 
42. Van Winter JT, Noller KL, Zimmerman D, Melton $\amalg$. Natural history of premature thelarche in Olmsted County, Minnesota, 1940 to 1984. J Pediatr. 1990;116(2):278-280. doi: https://doi.org/10.1016/S0022-3476(05)82891-4

43. de Vries L, Horev G, Schwartz M, Phillip M. Ultrasonographic and clinical parameters for early differentiation between precocious puberty and premature thelarche. Eur J Endocrinol. 2006;154(6):891-898. doi: https://doi.org/10.1530/eje.1.02151

44. Millar DM, Blake JM, Stringer DA, et al. Prepubertal Ovarian Cyst Formation: 5 Years'Experience. J Diagnostic Med Sonogr. 1993;9(3):168-168. doi: https://doi.org/10.1177/875647939300900331

45. de Sousa G, Wunsch R, Andler W. Precocious pseudopuberty due to autonomous ovarian cysts: A report of ten cases and long-term follow-up. Hormones. 2008;7(2):170-174. doi: https://doi.org/10.1007/BF03401509

46. Papanikolaou A, Michala L. Autonomous Ovarian Cysts in Prepubertal Girls. How Aggressive Should We Be? A Review of the Literature. J Pediatr Adolesc Gynecol. 2015;28(5):292-296. doi: https://doi.org/10.1016/j.jpag.2015.05.004

47. Papadimitriou A, Beri D, Tsialla A, et al. Early growth acceleration in girls with idiopathic precocious puberty. J Pediatr. 2006;149(1):43-46. doi: https://doi.org/10.1016/j.jpeds.2006.02.005

48. Fontoura M, Brauner R, Prevot C, Rappaport R. Precocious puberty in girls: early diagnosis of a slowly progressing variant. Arch Dis Child. 1989;64(8):1170-1176. doi: https://doi.org/10.1136/adc.64.8.1170

49. Ladjouze A, Soskin S, Garel C, et al. GH deficiency with central precocious puberty: A new rare disorder associated with a developmental defect of the hypothalamic-pituitary area. Eur J Endocrinol. 2007;156(4):463-469. doi: https://doi.org/10.1530/EJE-06-0688

50. Burke AB, Collins MT, Boyce AM. Fibrous dysplasia of bone: craniofacial and dental implications. Oral Dis. 2017;23(6):697-708. doi: https://doi.org/10.1111/odi.12563

51. Robinson C, Collins MT, Boyce AM. Fibrous Dysplasia/McCune-Albright Syndrome: Clinical and Translational Perspectives. Curr Osteoporos Rep. 2016;14(5):178-186. doi: https://doi.org/10.1007/s11914-016-0317-0

52. Kim I-S, Kim ER, Nam HJ, et al. Activating Mutation of GSa in McCune-Albright Syndrome Causes Skin Pigmentation by Tyrosinase Gene Activation on Affected Melanocytes. Horm Res Paediatr. 1999;52(5):235-240. doi: https://doi.org/10.1159/000023467

53. Cisternino M, Arrigo T, Pasquino AM, et al. Etiology and Age Incidence of Precocious Puberty in Girls: A Multicentric Study. J Pediatr Endocrinol Metab. 2000;13(1):695-701. doi: https://doi.org/10.1515/JPEM.2000.13.S1.695

54. Marshall WA, Tanner JM. Variations in the Pattern of Pubertal Changes in Boys. Arch Dis Child. 1970;45(239):13-23. doi: https://doi.org/10.1136/adc.45.239.13

55. Marshall WA, Tanner JM. Variations in pattern of pubertal changes in girls. Arch Dis Child. 1969:44(235):291-303. doi: https://doi.org/10.1136/adc.44.235.291

56. Neely EK, Hintz RL, Wilson DM, et al. Normal ranges for immunochemiluminometric gonadotropin assays. J Pediatr. 1995:127(1):40-46. doi: https://doi.org/10.1016/S0022-3476(95)70254-7

57. Neely EK, Wilson DM, Lee PA, et al. Spontaneous serum gonadotropin concentrations in the evaluation of precocious puberty. J Pediatr. 1995;127(1):47-52. doi: https://doi.org/10.1016/S0022-3476(95)70255-5

58. Houk CP, Kunselman AR, Lee PA. Adequacy of a Single Unstimulated Luteinizing Hormone Level to Diagnose Central Precocious Puberty in Girls. Pediatrics. 2009;123(6):e1059-e1063. doi: https://doi.org/10.1542/peds.2008-1180

59. Resende EAMR, Lara BHJ, Reis JD, et al. Assessment of Basal and Gonadotropin-Releasing Hormone-Stimulated Gonadotropins by Immunochemiluminometric and Immunofluorometric Assays in Normal Children. J Clin Endocrinol Metab. 2007;92(4):1424-1429. doi: https://doi.org/10.1210/jc.2006-1569

60. Bay K, Andersson A-M, Skakkebaek NE. Estradiol levels in prepubertal boys and girls - analytical challenges. Int J Androl. 2004;27(5):266-273. doi: https://doi.org/10.1111/j.1365-2605.2004.00487.x

61. Harrington J, Palmert MR, Hamilton J. Use of local data to enhance uptake of published recommendations: an example from the diagnostic evaluation of precocious puberty. Arch Dis Child. 2014;99(1):15-20. doi: https://doi.org/10.1136/archdischild-2013-304414

62. Lee D-M, Chung I-H. Morning basal luteinizing hormone, a good screening tool for diagnosing central precocious puberty. Ann Pediatr Endocrino/ Metab. 2019;24(1):27-33. doi: https://doi.org/10.6065/ apem.2019.24.1.27
63. Bangalore Krishna K, Fuqua JS, Rogol AD, et al. Use of Gonadotropin-Releasing Hormone Analogs in Children: Update by an International Consortium. Horm Res Paediatr. 2019;91(6):357-372. doi: https://doi.org/10.1159/000501336

64. Kuiri-Hänninen T, Sankilampi U, Dunkel L. Activation of the Hypothalamic-Pituitary-Gonadal Axis in Infancy: Minipuberty. Horm Res Paediatr. 2014;82(2):73-80. doi: https://doi.org/10.1159/000362414

65. Bizzarri C, Spadoni GL, Bottaro G, et al. The Response to Gonadotropin Releasing Hormone (GnRH) Stimulation Test Does Not Predict the Progression to True Precocious Puberty in Girls With Onset of Premature Thelarche in the First Three Years of Life. J Clin Endocrinol Metab. 2014;99(2):433-439. doi: https://doi.org/10.1210/jc.2013-3292

66. Pescovitz $\mathrm{OH}$, Hench KD, Barnes KM, et al. Premature Thelarche and Central Precocious Puberty: The Relationship Between Clinical Presentation and the Gonadotropin Response to Luteinizing Hormone-Releasing Hormone. J Clin Endocrinol Metab. 1988:67(3):474-479. doi: https://doi.org/10.1210/jcem-67-3-474

67. Oerter KE, Uriarte MM, Rose SR, et al. Gonadotropin Secretory Dynamics During Puberty in Normal Girls and Boys. J Clin Endocrinol Metab. 1990;71(5):1251-1258. doi: https://doi.org/10.1210/jcem-71-5-1251

68. Neely EK, Hintz RL, Wilson DM, et al. Normal ranges for immunochemiluminometric gonadotropin assays. J Pediatr. 1995;127(1):40-46. doi: https://doi.org/10.1016/S0022-3476(95)70254-7

69. Brito VN. Diagnostic Value of Fluorometric Assays in the Evaluation of Precocious Puberty. J Clin Endocrinol Metab. 1999;84(10):3539-3544. doi: https://doi.org/10.1210/jc.84.10.3539

70. Brito VN, Latronico AC, Arnhold IJP, Mendonca BB. A Single Luteinizing Hormone Determination 2 Hours after Depot Leuprolide Is Useful for Therapy Monitoring of GonadotropinDependent Precocious Puberty in Girls. J Clin Endocrinol Metab. 2004;89(9):4338-4342. doi: https://doi.org/10.1210/jc.2003-031537

71. Pasternak Y, Friger M, Loewenthal $N$, et al. The utility of basal serum LH in prediction of central precocious puberty in girls. Eur J Endocrinol. 2012;166(2):295-299. doi: https://doi.org/10.1530/EJE-11-0720

72. Sathasivam A, Garibaldi L, Shapiro S, et al. Original article: Leuprolide stimulation testing for the evaluation of early female sexual maturation. Clin Endocrinol (Oxf). 2010;73(3):375-381. doi: https://doi.org/10.1111/j.1365-2265.2010.03796.x

73. Lee DS, Ryoo NY, Lee SH, et al. Basal luteinizing hormone and follicular stimulating hormone: is it sufficient for the diagnosis of precocious puberty in girls? Ann Pediatr Endocrinol Metab. 2013;18(4):196. doi: https://doi.org/10.6065/apem.2013.18.4.196

74. Freire AV, Escobar ME, Gryngarten MG, et al. High diagnostic accuracy of subcutaneous Triptorelin test compared with GnRH test for diagnosing central precocious puberty in girls. Clin Endocrinol (Oxf). 2013;78(3):398-404. doi: https://doi.org/10.1111/j.1365-2265.2012.04517.x

75. Eckert $\mathrm{KL}$, Wilson DM, Bachrach LK, et al. A single-sample, subcutaneous gonadotropin-releasing hormone test for central precocious puberty. Pediatrics. 1996;97:517-519.

76. Roger M, Lahlou N, Chaussain JL. Gonadotropin-releasing hormone testing in pediatrics. In: Ranke MB, ed. Diagnostics of Endocrine Function in Children and Adolescents. Heidelberg, Germany: Johann Ambrosius Barth; 1996. P. 346-369

77. Wilson DA, Hofman PL, Miles HL, et al. Evaluation of the buserelin stimulation test in diagnosing gonadotropin deficiency in males with delayed puberty. J Pediatr. 2006;148(1):89-94 doi: https://doi.org/10.1016/j.jpeds.2005.08.045

78. Khadilkar V, Khadilkar A, Prasad $\mathrm{H}$, et al. Evaluation of $\mathrm{GnRH}$ analogue testing in diagnosis and management of children with pubertal disorders. Indian J Endocrinol Metab. 2012;16(3):400. doi: https://doi.org/10.4103/2230-8210.95682

79. Болмасова А.В. Оптимизация ростового прогноза у детей с гонадотропинзависимыми формами преждевременного полового развития опухолевого и неопухолевого генеза: Дис. ...канд. мед. наук. - М.; 2012. [Bolmasova AV. Optimizatsiya rostovogo prognoza u detei s gonadotropinzavisimymi formami prezhdevremennogo polovogo razvitiya opukholevogo i neopukholevogo geneza. [dissertation] Moscow; 2012. (In Russ.)].

80. Chudecka-Głaz A, Rzepka-Górska I, Kosmowska B, Głaz C. The levels of selected hormones in serum and ovarian cyst fluid in girls and young women. Ginekol Pol. 1999;70(5):236-241. 
81. Padilla SL. Androgen-producing tumors in children and adolescents. Adolesc Pediatr Gynecol. 1989;2(3):135-142. doi: https://doi.org/10.1016/S0932-8610(89)80003-9

82. Englund AT. Pediatric Germ Cell and Human Chorionic Gonadotropin — Producing Tumors. Am J Dis Child. 1991;145(11):1294 doi: https://doi.org/10.1001/archpedi.1991.02160110086026

83. Livadas S, Dracopoulou M, Dastamani A, et al. The spectrum of clinical, hormonal and molecular findings in 280 individuals with nonclassical congenital adrenal hyperplasia caused by mutations of the CYP21A2 gene. Clin Endocrinol (Oxf). 2015;82(4):543-549. doi: https://doi.org/10.1111/cen.12543

84. Razavi Z., RastgooHaghi A. Precocious Puberty Associated with an Adrenal Tumor: A case report. Iran J Ped Hematol Oncol. 2016;16(2):136-141

85. Goyal A, Malhotra R, Khadgawat R. Precocious pseudopuberty due to virilising adrenocortical carcinoma progressing to central precocious puberty after surgery. BMJ Case Rep. 2019;12(3):e229476. doi: https://doi.org/10.1136/bcr-2019-229476

86. Kafi SE, Alagha E, Shazly MA, Al-Agha A. Pseudo-precocious Puberty Associated with an Adrenocortical Tumor in a Young Child. Cureus. 2019:11(12):e6440. doi: https://doi.org/10.7759/cureus.6440

87. Armengaud J-B, Charkaluk M-L, Trivin C, et al. Precocious Pubarche: Distinguishing Late-Onset Congenital Adrenal Hyperplasia from Premature Adrenarche. J Clin Endocrinol Metab. 2009;94(8):2835-2840. doi: https://doi.org/10.1210/jc.2009-0314

88. Comite F, Schiebinger RJ, Albertson BD, et al. Isosexual Precocious Pseudopuberty Secondary to a Feminizing Adrenal Tumor. J Clin Endocrinol Metab. 1984;58(3):435-440. doi: https://doi.org/10.1210/jcem-58-3-435

89. Tanner JM, Whitehouse RH, Marshall WA, et al. Assessment of Skeletal Maturity and Prediction of Adult Height (TW2 Method). New York: Academic Press\$1975.

90. Vejvoda M, Grant DB. Discordant bone maturation of the hand in children with precocious puberty and congenital adrenal hyperplasia. Acta Paediatr. 1981;70(6):903-905. doi: https://doi.org/10.1111/j.1651-2227.1981.tb06248.x

91. Жуковский М.А., Бухман А.И. Сроки окостенения скелета кисти и дистального отдела предплечья у детей и подростков г. Москвы / В кн. Детская эндокринология: Руководство для врачей. - М.: Медицина; 1995. C. 40. [Zhukovskii MA Bukhman Al. Sroki okosteneniya skeleta kisti i distal'nogo otdela predplech'ya u detei i podrostkov g. Moskvy In: Detskaya endokrinologiya: Rukovodstvo dlya vrachei. Moscow: Meditsina; 1995. P. 40. (In Russ.)].

92. Greulich W, Pyle S. Radiographic Atlas of Skeletal Development of the Hand and Wrist. Stanford, Calif: Stanford University Press; 1999.

93. Bull RK, Edwards PD, Kemp PM, et al. Bone age assessment: a large scale comparison of the Greulich and Pyle, and Tanner and Whitehouse (TW2) methods. Arch Dis Child. 1999;81(2):172-173. doi: https://doi.org/10.1136/adc.81.2.172

94. Fahmy JL, Kaminsky CK, Kaufman F, et al. The radiological approach to precocious puberty. Br J Radiol. 2000;73(869):560-567. doi: https://doi.org/10.1259/bjr.73.869.10884758

95. Martin DD, Stahl K, Schweizer R, et al. Validation of BoneXpert in children with precocious puberty. Horm Res 2008;70(1):73.

96. Breen MA, Tsai A, Stamm A, Kleinman PK. Bone age assessment practices in infants and older children among Society for Pediatric Radiology members. Pediatr Radiol. 2016;46(9):1269-1274. doi: https://doi.org/10.1007/s00247-016-3618-7

97. Xu Y-Q, Li G-M, Li Y. Advanced bone age as an indicator facilitates the diagnosis of precocious puberty. J Pediatr (Rio J). 2018;94(1):69-75. doi: https://doi.org/10.1016/j.jped.2017.03.010

98. Martin DD, Wit JM, Hochberg Z, et al. The Use of Bone Age in Clinical Practice - Part 2. Horm Res Paediatr. 2011;76(1):10-16. doi: https://doi.org/10.1159/000329374

99. Mogensen SS, Aksglaede L, Mouritsen A, et al. Pathological and Incidental Findings on Brain MRI in a Single-Center Study of 229 Consecutive Girls with Early or Precocious Puberty. PLoS One. 2012;7(1):e29829. doi: https://doi.org/10.1371/journal.pone.0029829

100. Lee J, Kim J, Yang A, et al. Etiological trends in male central precocious puberty. Ann Pediatr Endocrinol Metab. 2018;23(2):75-80. doi: https://doi.org/10.6065/apem.2018.23.2.75

101. Kaplowitz PB. Do 6-8 year old girls with central precocious puberty need routine brain imaging? Int J Pediatr Endocrinol. 2016;2016(1):9. doi: https://doi.org/10.1186/s13633-016-0027-5
102. Kim I, Young RH, Scully RE. Leydig cell tumors of the testis. Am J Surg Pathol. 1985;9(3):177-192. doi: https://doi.org/10.1097/00000478-198503000-00002

103. Cecchetto $G$, Alaggio R, Bisogno $G$, et al. Sex cord-stromal tumors of the testis in children. A clinicopathologic report from the Italian TREP project. J Pediatr Surg. 2010;45(9):1868-1873. doi: https://doi.org/10.1016/j.jpedsurg.2010.02.120

104. Wendt S, Shelso J, Wright K, Furman W. Neoplastic causes of abnormal puberty. Pediatr Blood Cancer. 2014;61(4):664-671. doi: https://doi.org/10.1002/pbc.24825

105. Alagha E, Kafi SE, Shazly MA, Al-Agha A. Precocious Puberty Associated with Testicular Hormone-secreting Leydig Cell Tumor. Cureus. December 2019;11(12):e6441. doi: https://doi.org/10.7759/cureus.6441

106. Haber HP, Wollmann HA, Ranke MB. Pelvic ultrasonography: Early differentiation between isolated premature thelarche and central precocious puberty. Eur J Pediatr. 1995;154(3):182-186. doi: https://doi.org/10.1007/BF01954267

107. Sathasivam A, Rosenberg HK, Shapiro S, et al. Pelvic Ultrasonography in the Evaluation of Central Precocious Puberty: Comparison with Leuprolide Stimulation Test. J Pediatr. 2011;159(3):490-495. doi: https://doi.org/10.1016/j.jpeds.2011.02.032

108. Badouraki M, Christoforidis A, Economou l, et al. Evaluation of pelvic ultrasonography in the diagnosis and differentiation of various forms of sexual precocity in girls. Ultrasound Obstet Gynecol. 2008;32(6):819-827. doi: https://doi.org/10.1002/uog.6148

109. Kang E, Cho JH, Choi J-H, Yoo H-W. Etiology and therapeutic outcomes of children with gonadotropin-independent precocious puberty. Ann Pediatr Endocrinol Metab. 2016;21(3):136. doi: https://doi.org/10.6065/apem.2016.21.3.136

110. Schneider DT, Terenziani M, Cecchetto G. et al., editors. Gonadal and extragonadal germ cell tumors, sex cord stromal and rare gonadal tumors. In: Rare Tumors in Children and Adolescents. Germany: Springer Berlin Heidelberg; 2102. P. 327-402.

111. Parida L. Nonurological malignancies in children. J Indian Assoc Pediatr Surg. 2014;19:31-37. doi: https://doi.org/10.4103/0971-9261.125960

112. Lin $X, W u D$, Zheng $N$, et al. Gonadal germ cell tumors in children. Medicine (Baltimore). 2017;96(26):e7386. doi: https://doi.org/10.1097/MD.0000000000007386

113. Javaid MK, Boyce A, Appelman-Dijkstra N, et al. Best practice management guidelines for fibrous dysplasia/McCuneAlbright syndrome: a consensus statement from the FD/MAS international consortium. Orphanet J Rare Dis. 2019;14(1):139. doi: https://doi.org/10.1186/s13023-019-1102-9

114. Mulder RL, Kremer LCM, Santen HM van, et al. Prevalence and risk factors of radiation-induced growth hormone deficiency in childhood cancer survivors: A systematic review. Cancer Treat Rev. 2009;35(7):616-632. doi: https://doi.org/10.1016/j.ctrv.2009.06.004

115. van lersel L, Li Z, Srivastava DK, et al. Hypothalamic-Pituitary Disorders in Childhood Cancer Survivors: Prevalence, Risk Factors and Long-Term Health Outcomes. J Clin Endocrinol Metab. 2019;104(12):6101-6115. doi: https://doi.org/10.1210/jc.2019-00834

116. Costin G, Kaufman F. Hypopituitarism and precocious puberty (pp). Pediatr Res. 1984;18(1):166A-166A doi: https://doi.org/10.1203/00006450-198404001-00437

117. Darzy KH, Shalet SM. Hypopituitarism following radiotherapy. Pituitary 2009;12(1):40-50. doi: https://doi.org/10.1007/s11102-008-0088-4

118. Darzy KH. Radiation-induced hypopituitarism after cancer therapy: who, how and when to test. Nat Clin Pract Endocrinol Metab. 2009;5(2):88-99. doi: https://doi.org/10.1038/ncpendmet1051

119. Bangalore Krishna K, Fuqua JS, Rogol AD, et al. Use of GonadotropinReleasing Hormone Analogs in Children: Update by an International Consortium. Horm Res Paediatr. 2019;91(6):357-372. doi: https://doi.org/10.1159/000501336

120. Постановление Правительства РФ от 26.04.2012 N 403 (ред. от 20.11.2018) «О порядке ведения Федерального регистра лиц, страдающих жизнеугрожающими и хроническими прогрессирующими редкими (орфанными) заболеваниями, приводящими к сокращению продолжительности жизни граждан или их инвалидности, и его регионального сегмента». [Federal Law of Russian Federation №403 of 26.04.2012 (Ed. 20.11.2018) «O poryadke vedeniya Federal'nogo registra lits, stradayushchikh zhizneugrozhayushchimi i khronicheskimi progressiruyushchimi redkimi (orfannymi) zabolevaniyami, privodyashchimi k sokrashcheniyu prodolzhitel'nosti zhizni grazhdan ili ikh invalidnosti, i ego regional'nogo segmenta». (In Russ.)]. 
121. Lazar L, Padoa A, Phillip M. Growth Pattern and Final Height after Cessation of Gonadotropin-Suppressive Therapy in Girls with Central Sexual Precocity. J Clin Endocrinol Metab. 2007;92(9):3483-3489. doi: https://doi.org/10.1210/jc.2007-0321

122. Parker KL, Baens-Bailon RG, Lee PA. Depot Leuprolide Acetate Dosage for Sexual Precocity*. J Clin Endocrinol Metab. 1991;73(1):50-52. doi: https://doi.org/10.1210/jcem-73-1-50

123. Partsch, E von Büren, M Bra C-J. Efficacy of the subcutaneous reformulated triptorelin depot in children with central precocious puberty. Acta Paediatr. 1998;87(12):1240-1244 doi: https://doi.org/10.1080/080352598750030906

124. Tatò L, Savage MO, Antoniazzi F, et al. Optimal Therapy of Pubertal Disorders in Precocious/Early Puberty. J Pediatr Endocrinol Metab. 2001;14(2):985-995. doi: https://doi.org/10.1515/jpem-2001-s211

125. Antoniazzi F, Zamboni G. Central Precocious Puberty. Pediatr Drugs. 2004;6(4):211-231. doi: https://doi.org/10.2165/00148581-200406040-00002

126. Yilmaz GC, Kara C, Bitkin EC, Aydin HM. Comparison of Triptorelin Versus Leuprolide in Treatment of Girls with Central Precocious Puberty. In European Society for Paediatric Endocrinology; [Internet] 2016 [cited 2019 Dec 9]. Available from: http://abstracts.eurospe.org/hrp/0086/hrp0086p2-p778.

127. Lahlou N, Carel J-C, Chaussain J-L, Roger M. Pharmacokinetics and Pharmacodynamics of GnRH Agonists: Clinical Implications in Pediatrics. J Pediatr Endocrinol Metab. 2000;13(1):723-737. doi: https://doi.org/10.1515/JPEM.2000.13.S1.723

128. Boepple PA, Mansfield MJ, Wierman ME, et al. Use of a Potent, Long Acting Agonist of Gonadotropin-Releasing Hormone in the Treatment of Precocious Puberty*. Endocr Rev. 1986;7(1):24-33. doi: https://doi.org/10.1210/edrv-7-1-24

129. Cook JS, Doty KL, Conn PM, Hansen JR. Assessment of depot leuprolide acetate dose-adequacy for central precocious puberty. J Clin Endocrinol Metab. 1992;74(5):1206-1209. doi: https://doi.org/10.1210/jcem.74.5.1569169

130. Carel J-C, Lahlou N, Guazzarotti L, et al. Treatment of central precocious puberty with depot leuprorelin. Eur J Endocrinol 1995;132(6):699-704. doi: https://doi.org/10.1530/eje.0.1320699

131. Lawson ML, Cohen N. A Single Sample Subcutaneous Luteinizing Hormone (LH)-Releasing Hormone (LHRH) Stimulation Test for Monitoring LH Suppression in Children with Central Precocious Puberty Receiving LHRH Agonists 1. J Clin Endocrinol Metab. 1999;84(12):4536-4540. doi: https://doi.org/10.1210/jcem.84.12.6181

132. Brito VN, Latronico AC, Arnhold IJP, Mendonca BB. A Single Luteinizing Hormone Determination 2 Hours after Depot Leuprolide Is Useful for Therapy Monitoring of GonadotropinDependent Precocious Puberty in Girls. J Clin Endocrinol Metab. 2004;89(9):4338-4342. doi: https://doi.org/10.1210/jc.2003-031537

133. Carel J-C, Blumberg J, Seymour C, et al. Three-month sustainedrelease triptorelin $(11.25 \mathrm{mg})$ in the treatment of central precocious puberty. Eur J Endocrinol. 2006;154(1):119-124. doi: https://doi.org/10.1530/eje.1.02056

134. Badaru A, Wilson DM, Bachrach LK, et al. Sequential Comparisons of One-Month and Three-Month Depot Leuprolide Regimens in Central Precocious Puberty. J Clin Endocrinol Metab. 2006;91(5):1862-1867. doi: https://doi.org/10.1210/jc.2005-1500

135. Latronico AC, Brito VN, Carel J-C. Causes, diagnosis, and treatment of central precocious puberty. Lancet Diabetes Endocrinol. 2016;4(3):265-274. doi: https://doi.org/10.1016/S2213-8587(15)00380-0

136. Bangalore Krishna K, Fuqua JS, Rogol AD, et al. Use of Gonadotropin-Releasing Hormone Analogs in Children: Update by an International Consortium. Horm Res Paediatr. 2019;91:1-16. doi: https://doi.org/10.1159/000501336

137. Федеральные клинические рекомендации (протоколы) по ведению детей Ф32 с эндокринными заболеваниями / Под ред. Дедова И.И., Петерковой В.А. - М.: Практика; 2014. - C. 277-294. [Federal'nye klinicheskie rekomendatsii (protokoly) po vedeniyu detei F32 s endokrinnymi zabolevaniyami. Ed by Dedova II, Peterkovoi VA. Moscow: Praktika; 2014. P. 277-294. (In Russ.)].

138. Приказ Министерства здравоохранения и социального развития Российской Федерации от 5.05.2012 г. №502н «Об утверждении порядка создания и деятельности врачебной комиссии медицинской организации». [Prikaz Ministerstva zdravookhraneniya i sotsial'nogo razvitiya Rossiiskoi Federatsii ot 5.05.2012. №502n «Ob utverzhdenii poryadka sozdaniya i deyatel'nosti vrachebnoi komissii meditsinskoi organizatsii». (In Russ.)].
139. Mieszczak J, Lowe ES, Plourde P, Eugster EA The Aromatase Inhibitor Anastrozole Is Ineffective in the Treatment of Precocious Puberty in Girls with McCune-Albright Syndrome. J Clin Endocrinol Metab. 2008;93(7):2751-2754. doi: https://doi.org/10.1210/jc.2007-2090

140. Estrada A, Boyce AM, Brillante BA, et al. Long-term outcomes of letrozole treatment for precocious puberty in girls with McCune-Albright syndrome. Eur J Endocrinol. 2016;175(5):477-483. doi: https://doi.org/10.1530/EJE-16-0526

141. Feuillan P, Calis K, Hill S, et al. Letrozole Treatment of Precocious Puberty in Girls with the McCune-Albright Syndrome: A Pilot Study. J Clin Endocrinol Metab. 2007:92(6):2100-2106. doi: https://doi.org/10.1210/jc.2006-2350

142. Eugster EA, Rubin SD, Reiter EO, et al. Tamoxifen treatment for precocious puberty in McCune-Albright syndrome: a multicenter trial. J Pediatr. 2003;143(1):60-66. doi: https://doi.org/10.1016/S0022-3476(03)00128-8

143. de G. Buff Passone C, Kuperman H, Cabral de Menezes-Filho H, et al. Tamoxifen Improves Final Height Prediction in Girls with McCune-Albright Syndrome: A Long Follow-Up. Horm Res Paediatr 2015:84(3):184-189. doi: https://doi.org/10.1159/000435881

144. Sims EK, Garnett S, Guzman F, et al. Fulvestrant treatment of precocious puberty in girls with McCune-Albright syndrome. Int J Pediatr Endocrinol. 2012;2012(1):26. doi: https://doi.org/10.1186/1687-9856-2012-26

145. Kreher NC, Pescovitz OH, Delameter $P$, et al. Treatment of familial male-limited precocious puberty with bicalutamide and anastrozole. J Pediatr. 2006;149(3):416-420. doi: https://doi.org/10.1016/j.jpeds.2006.04.027

146. Reiter EO, Mauras N, McCormick K, et al. Bicalutamide plus Anastrozole for the Treatment of Gonadotropin-Independent Precocious Puberty in Boys with Testotoxicosis: A Phase II, OpenLabel Pilot Study (BATT). J Pediatr Endocrinol Metab. 2010;23(10). doi: https://doi.org/10.1515/jpem.2010.161

147. Tessaris D, Matarazzo P, Mussa A, et al. Combined treatment with bicalutamide and anastrozole in a young boy with peripheral precocious puberty due to McCune-Albright Syndrome. Endocr J. 2012;59(2):111-117. doi: https://doi.org/10.1507/endocrj.EJ11-0214

148. Güven A, Nurcan Cebeci A, Hancili S. Gonadotropin releasing hormone analog treatment in children with congenital adrenal hyperplasia complicated by central precocious puberty. Hormones. 2015;14(2):265. doi: https://doi.org/10.14310/horm.2002.1555

149. Pescovitz OH, Comite F, Cassorla F, et al. True Precocious Puberty Complicating Congenital Adrenal Hyperplasia: Treatment with a Luteinizing Hormone-Releasing Hormone Analog*. J Clin Endocrinol Metab. 1984;58(5):857-861 doi: https://doi.org/10.1210/jcem-58-5-857

150. Brito VN, Spinola-Castro AM, Kochi C, et al. Central precocious puberty: Revisiting the diagnosis and therapeutic management. Arch Endocrinol Metab. 2016;60(2):163-172. doi: https://doi.org/10.1590/2359-3997000000144

151. Breen JL, Maxson WS. Ovarian tumors in children and adolescents. Clinical Obstetrics Gynecol. 1977:20(3):607e23.

152. Mayer SK, Oligny LL, Deal C, et al. Childhood adrenocortical tumors: Case series and reevaluation of prognosis A 24-year experience. J Pediatr Surg. 1997;32(6):911. doi: https://doi.org/10.1016/S0022-3468(97)90649-7

153. Cheville JC, Sebo TJ, Lager DJ, et al. Leydig cell tumor of the testis: A clinicopathologic, DNA content, and MIB-1 comparison of nonmetastasizing and metastasizing tumors. Am J Surg Pathol. 1998;22(11):1361. doi: https://doi.org/10.1097/00000478-199811000-00006

154. Michalkiewicz E, Sandrini R, Figueiredo B, et al. Clinical and Outcome Characteristics of Children With Adrenocortical Tumors: A Report From the International Pediatric Adrenocortical Tumor Registry. J Clin Oncol. 2004;22(5):838-845. doi: https://doi.org/10.1200/JCO.2004.08.085

155. Murray MJ, Bartels U, Nishikawa R, et al. Consensus on the management of intracranial germ-cell tumours. Lancet Oncol. 2015;16(9):e470-e477. doi: https://doi.org/10.1016/S1470-2045(15)00244-2

156. Клинические рекомендации «Экстракраниальные герминогенноклеточные опухоли у детей» разработанные Национальным обществом детских гематологов, онкологов. 2020. [Klinicheskie rekomendatsii «Ekstrakranial'nye germinogenno-kletochnye opukholi u detei» razrabotannye Natsional'nym obshchestvom detskikh gematologov, onkologov. 2020. (In Russ.)]. Доступно по ссылке: https://cr.minzdrav.gov.ru/schema/69_1\#doc_b 
Рукопись получена: 24.09.2021. Одобрена к публикации: 25.09.2021. Опубликована online: 30.10.2021.

\section{ИНФОРМАЦИЯ ОБ АВТОРАХ [AUTHORS INFO]}

*Зубкова Наталья Анатольевна, к.м.н. [Natalia A. Zubkova, MD]; адрес: Россия, 117292, Москва, ул. Дмитрия Ульянова, д. 11 [address: 11 Dm. Ulyanova street, 117292, Moscow, Russia]; eLibrary SPIN: 5064-9992;

ORCID: https://orcid.org/0000-0001-6097-7831; e-mail: zunata2006@yandex.ru

Алимова Ирина Леонидовна, д.м.н., професcop [Irina L. Alimova, MD, PhD, Professor]; eLibrary SPIN: 4583-9822; ORCID: https://orcid.org/0000-0003-3230-1337; e-mail: iri-alimova@yandex.ru

Башнина Елена Борисовна, Д.м.н. [Elena B. Bashnina, PhD]; eLibrary SPIN: 5568-0690;

ORCID https://orcid.org/0000-0002-7063-1161; e-mail: bashnina@mail.ru

Безлепкина Ольга Борисовна, д.М.н. [Olga B. Bezlepkina, MD]; eLibrary SPIN: 3884-0945;

ORCID: https://orcid.org/0000-0001-9621-5732; e-mail: olgabezlepkina@mail.ru

Болотова Нина Викторовна, Д.м.Н. [Nina V. Bolotova, MD]; eLibrary SPIN: 5061-1600;

ORCID: https://orcid.org/0000-0002-8148-526X; e-mail: kafedranv@mail.ru

Калинченко Наталья Юрьевна, К.M.H. [Natalya Y. Kalinchenko, MD, PhD]; eLibrary SPIN: 6727-9653;

ORCID: https://orcid.org/0000-0002-2000-7694; e-mail: kalinnat@rambler.ru

Карева Мария Андреевна, д.м.н. [Maria A. Kareva, MD, PhD]; eLibrary SPIN: 5089-0310;

ORCID: https://orcid.org/0000-0003-1320-6561; e-mail: i_marusya@mail.ru

Кияев Алексей Васильевич, д.м.н. [Alexey V. Kiyaev, MD, PhD]; eLibrary SPIN: 7092-7894;

ORCID: https://orcid.org/0000-0002-5578-5242; e-mail: thyroend@mail.ru

Колодкина Анна Александровна, к.M.н. [Anna A. Kolodkina, MD, PhD]; eLibrary SPIN: 6705-6630;

ORCID: https://orcid.org/0000-0001-7736-5372; e-mail: anna_kolodkina@mail.ru

Кострова Ирина Борисовна [Irina B. Kostrova]: eLibrary SPIN: 9224-7047;

ORCID: https://orcid.org/0000-0003-0112-3785; e-mail: ira-kostrova@mail.ru

Маказан Надежда Викторовна, к.M.H. [Nadezhda V. Makazan, MD, PhD]; eLibrary SPIN: 7156-6517;

ORCID: https://orcid.org/0000-0003-3832-6367; e-mail: nmakazan@yandex.ru

Малиевский Олег Артурович, д.М.H. [Oleg A. Malievskiy, MD]; eLibrary SPIN: 6813-5061;

ORCID: https://orcid.org/0000-0003-2599-0867; e-mail: malievsky@list.ru

Орлова Елизавета Михайловна, д.м.н. [Orlova Elizaveta, PhD-MD]; eLibrary SPIN: 5221-4235;

ORCID: https://orcid.org/0000-0001-6196-5322; e-mail: elizaveta.orlova@mail.ru

Петеркова Валентина Александровна, д.м.н. [Valentina A. Peterkova, MD]; eLibrary SPIN: 4009-2463;

ORCID: https://orcid.org/0000-0002-5507-4627; e-mail: peterkovava@hotmail.com

Петряйкина Елена Ефимовна, д.м.н. [Elena E. Petryaykina, MD]; eLibrary SPIN: 5997-7464;

ORCID: https://orcid.org/0000-0002-8520-2378; e-mail: lepet_morozko@mail.ru

Самсонова Любовь Николаевна, д.м.н. [Lyubov N. Samsonova, MD, PhD]; eLibrary SPIN: 7117-0960;

ORCID: https://orcid.org/0000-0003-0208-4116; e-mail: samsonovarmapo@yandex.ru

Таранушенко Татьяна Евгеньевна, д.м.н., профессор [Tatiana E. Taranushenko, MD, Professor]; elibrary SPIN: 4777-0283; ORCID: https://orcid.org/0000-0003-2500-8001; e-mail: tetar@rambler.ru

\section{ЦИТИРОВАТЬ:}

Петеркова В.А., Алимова И.Л., Башнина Е.Б., Безлепкина О.Б., Болотова Н.В., Зубкова Н.А., Калинченко Н.Ю., Карева М.А., Кияев А.В., Колодкина А.А., Кострова И.Б., Маказан Н.В., Малиевский О.А., Орлова Е.М., Петряйкина Е.Е., Самсонова Л.Н., Таранушенко Т.Е. Клинические рекомендации «Преждевременное половое развитие» // Проблемы эндокринологии. 2021. — T. 67. — №5. - C. 84-103. doi: https://doi.org/10.14341/probl12821

\section{TO CITE THIS ARTICLE:}

Peterkova VA, Alimova IL, Bashnina EB, Bezlepkina OB, Bolotova NV, Zubkova NA, Kalinchenko NU, Kareva MA, Kiyaev AV, Kolodkina AA, Kostrova IB, Makazan NV, Malievskiy OA, Orlova EM, Petryaykina EE, Samsonova LN, Taranushenko TE. Clinical guidelines «Precocious puberty». Problems of Endocrinology. 2021;67(5):84-103. doi: https://doi.org/10.14341/probl12821 